\title{
قواعد ومعايير التفاعل الاجتماعي داخل الأسرة
}

\section{د. دفتاح على حسين بالحاج \\ كلية الآداب - جامعة مصراتة}

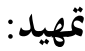

تناولت هذه الورقة البحثية المحددات الاجتماعية والاقتصادية وأثرها على قواعد ومعايير التفاعل الاجتماعي داخل الأسرة، وما يترتب على هذه المحددات من أنماط التفاعل من خلال عمليات الاتصال المتعلقة بمجريات الحياة اليومية، ونوع العلاقة بين الزوج والزوجة، وعلاقة الآباء بالأبناء، وعلاقة الأبناء فيما بينهم، وما يسود الأسرة من الدفء العاطفي والتقبل والاهتمام

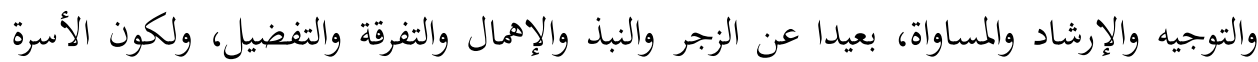
واعتبارها إحدى الركائز الأساسية في بناء جيل قادر على التفاعل مع غيره ويسهم في بناء المجتمع

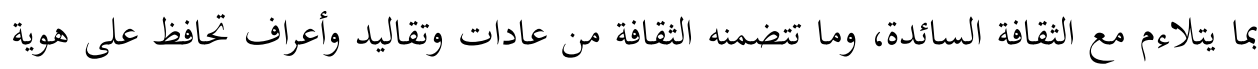
المجتمع، وتضبط سلوك أفراده وتحدد الأدوار والمكانات الاجتماعية لمما.

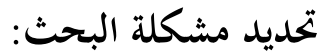

تعد القواعد والمعايير إحدى منظمات السلوك الإنساني داخل الأسرة، ويتشرب الفرد

هذه القواعد والمعايير من خلال الثقافة السائدة التي يتم اكتسابها عن طريق التفاعل مع الآخرين

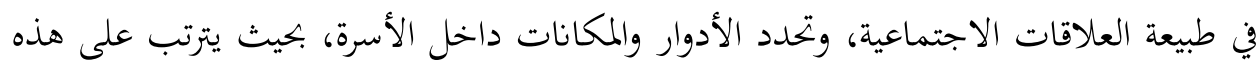
الأدوار والمكانات ما يعرف بالتبادل الاجتماعي من حيث الحقوق والواجبات، فوجبات دور معين هو حقوق للدور الآخر في المقابل، كما أنَ حقوق دور معين يعتبر واجبات للدور الثاني وهكذا في عملية اتصالية تبادلية تعبر عن التفاعل الاجتماعي بين أعضاء الأسرة، وهذه العملية

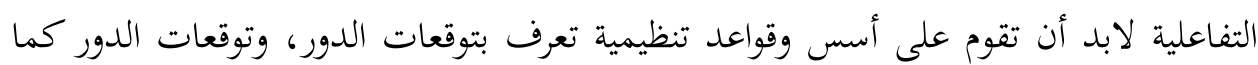
يعرفها تالكوت بارسونز: (( هي مجموعة من المعايير التي تحدد الكيفية التي يسلك بها من يشغل 
مكانة معينة ويؤدي دوراً يرتبط بتلك المكانة في موقف تفاعلي محدد )) (الذويبي،17،1998). ومن خلال العرض السابق للنقطة البحثية تم التوصل إلى وضع التساؤل الرئيسي الذي مفاده: إلى أي مدى تتبلور دور المحددات الاجتماعية والاقتصادية في تنظيم قواعد ومعايير التفاعل الاجتماعي داخل الأسرة؟ ومن خلال صياغة هذا التساؤل الرئيسي تمت صياغة الأسئلة

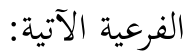

- هل ترتبط المكانة الاجتماعية للأسرة بقواعد ومعايير التفاعل الاجتماعي داخل

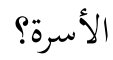

- هل يرتبط المستوى المعيشي للأسرة بقواعد ومعايير التفاعل الاجتماعي داخل

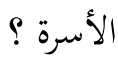

- هل ترتبط الخلفية الحضارية بقواعد ومعايير التفاعل الاجتماعي داخل الأسرة؟ - هل يرتبط المستوى التعليمي لأفراد الأسرة بقواعد ومعايير التفاعل داخل الأسرة ؟ - هل يرتبط حجم ونمط الأسرة بقواعد ومعايير التفاعل داخل الأسرة؟

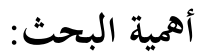
- تتحدد الأهمية العلمية والعملية نتيجة التغيرات السريعة التي طرأت على الأسرة في جميع مناحي الحياة، وخاصة في جوانبها الاجتماعية والاقتصادية وما انعكس ذلك على البناء الاجتماعي داخل الأسرة بقواعد ومعايير التفاعل. - إلقاء الضوء على واقع التفاعل داخل الأسرة الليبية، متخذا من الأسرة بمدينة مصراتة نموذجا. - إبراز مـدى التغير والتحـديث في المعايير التي تنهض عليها العلاقات الاجتماعية الأسرية المتعلقة بمجريات الحياة اليومية. - تشخيص العلاقـة القائمـة بـين العلاقـات الاجتماعيـة الأسـرية وملامسح المحـددات الاجتماعية والاقتصادية. - التعرف على مستوى درجات التفاعل داخل الأسرة بالمجتمع اللببي. 


\section{أهداف البحث:}

- محاولة التعرف على كيفية تأثير بعض المتغيرات المستقلة المتمثلة في المكانة الاجتماعية للأسرة، والمستوى المعيشي والتعليمي والخلفية الحضارية، وحجم الأسرة ونمطها بوصفها عوامل تحدد وتنظم قواعد ومعايير السلوك التي تقوم عليها عملية التفاعل في الأسرة.

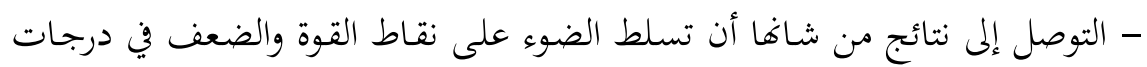
وقواعد التفاعل للبناء الاجتماعي الأسري الذي ينعكس على البناء الاجتماعي للمجتمع. المفاهيم والمصطلحات:

الححددات الاجتماعية الاقتصادية: ترتبط بالعوامل المحيطة بالفرد والأسرة وبالظروف المجتمعية المؤثرة في حياة الفرد ودوره الاجتماعي وعلاقته بالجوانب المادية واللامادية. المفهوم الإجرائي للمحددات الاجتماعية الاقتصادية: نقصد بها الظروف التي يعيش

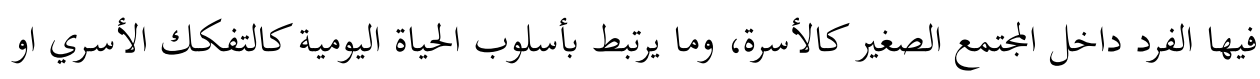
المستوى الاقتصادي المعيشي، والمستوى التعليمي والخلفية الحضارية. القواعد الاجتماعية: (( تعد القواعد الاجتماعية إحدى منظمات السلوك الإنساني، كما تعبر عن الظواهر الاجتماعية التي هي ليست فردية، بل عامة ومن وظائفها تحديد سلوك إكوال الشخص وتوجيهه بارتباطه نحو الآخرين من الجماعات الاجتماعية، علاوة على توجيه ارتباط

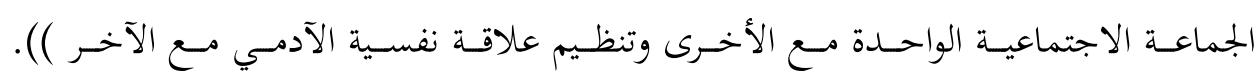

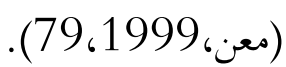

المفهوم الإجرائي للقواعد: نقصد بالقواعد السنن المكتوبة وغير المكتوبة التي يتشربها الفرد عن طريق تفاعله مع أسرته أثناء عملية التنشئة الاجتماعية، المتمثلة في العادات والتقاليد والأعراف والمعتقد، وغيرها من منظمات السلوك الإنساني، التي تحدد السلوك وتوجهه في تنظيم العلاقة مع الآخرين.

المعايير الاجتماعية: تعتبر المعايير الاجتماعية مصدرا للضغط على الإفراد لكي تتشابه

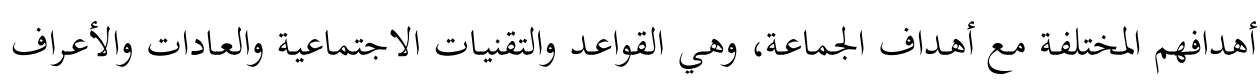


المعترف بهـا، والقيم والابتحاهـات السـائدة التي تعتبر مرشـدا للفـرد داخل الجماعـة تحـد سلوكه المقبول فيها (( المعايير تشمل عددا هائلا مـن نتائج تفاعل الجماعة في ماضيها وحاضرها مثل تركي

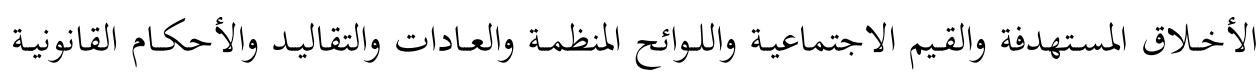
والعرف... ()). (عكاشة، 1996، 196). المفهوم الإجرائي للمعايير الاجتماعية: المعايير هي بمثابة المقياس الذي يحدد ما هو صواب وما هو خطا، وما هو جائز وما هو غير جائز، ومتى يكون مقبولا من الجماعة ملتزما بسلوكها ومسايرا لقواعدها والتي تم غرسها داخل الأسرة وما تشربته الأسرة من ثقافة المجتمع.

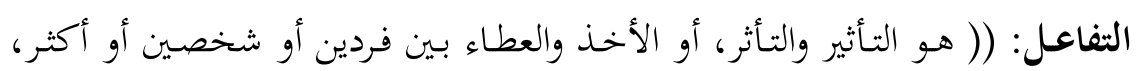
وقد يكون مباشرا أي وجها لوجه، وقد يحدث بشكل غير مباشر )). (معن، 1999، 83).

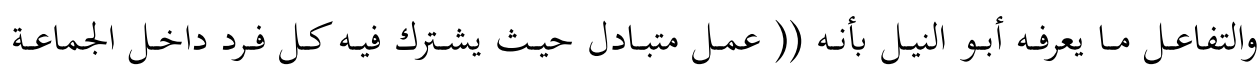

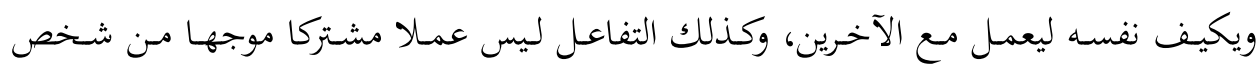

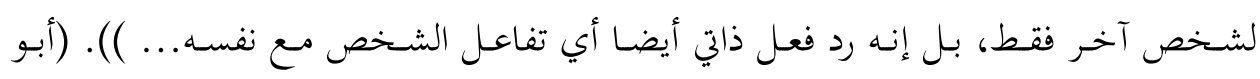
النيل،232،1978) المفهوم الإجرائي للتفاعل: عملية تؤثر في سلوك كل فرد من أفراد الجماعة الأسرية قد يكون هذا التأثير والتأثر سلبا أو إيجابا. التفاعل الاجتماعي: (( يحدث بوجود شرطين أساسيين: أولمما الاتصال الاجتماعي،

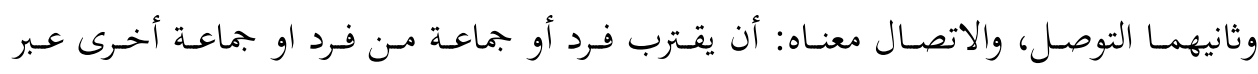

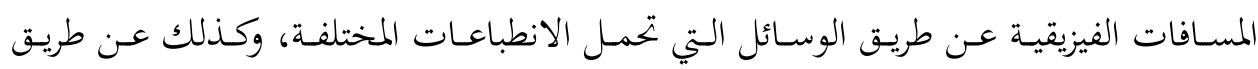


الاتصال الاجتماعي هو أول مراحل التفاعل )). (النجيحي، بدون، 185-186).

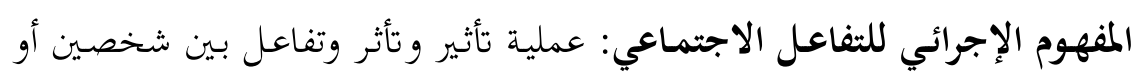
أكثر من خلال عمليات التنبيه والاستجابة، بحيث يحدث هذا التفاعل المشترك بين الفرد والأفراد 
الآخرين داخل الأسرة، أي تفاعل الآباء مع الأبناء والزوج مع الزوجة والأخ مع الأخ والأخت،

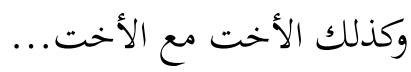

الأسرة: (( هي الوحدة الاجتماعية الأولى التي ينشأ فيها الطفل وهي المسؤولة على

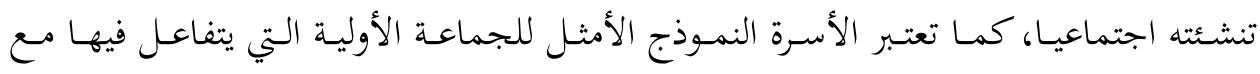

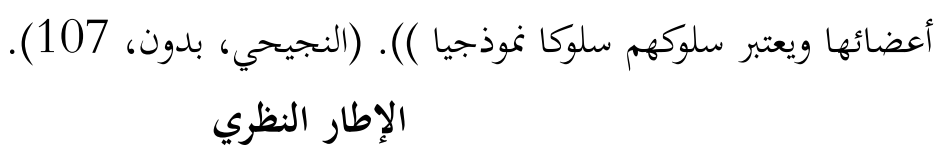
المعايير الاجتماعية كمحددات للتفاعل الاجتماعي:

المعايير الاجتماعية نتاج اجتماعي، أو هي نتاج لعلاقات التفاعل، فهي مكتسبة الماتية

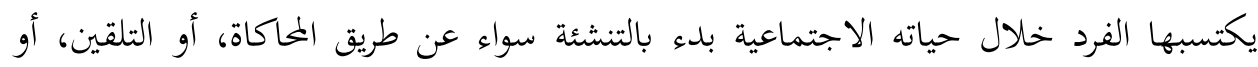
القدوة وهذه العملية تستمر مع الفرد طوال حياته، ويتفاعل معها حسب المواقف التي تواجهه، إلا أن هذه المعايير تختلف باختلاف الثقافات والجماعات حسب الزمان وان والمكانان، فهي نسبية من حيث الثبات والاستقرار كذلك قابلة للنمو والتطور والتبدل والتغير.

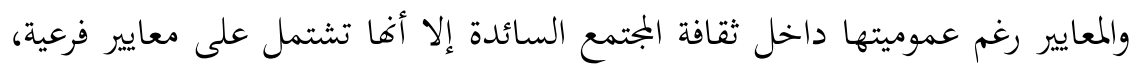

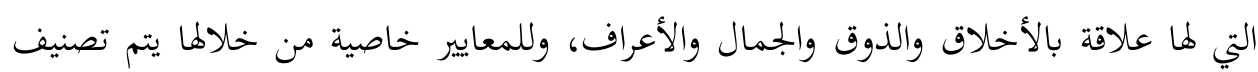
أنماط ومظاهر السلوك الذي يتماشى مع ثقافة المجتمع وما يكون سلوكا مقبولا فيتم تحديد الصواب والخطأ والقبول والرفض والسلوك السوي والمنحرف.

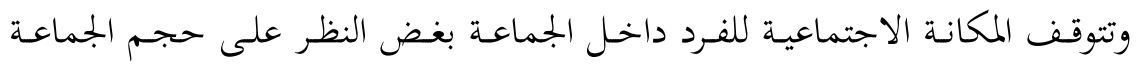
ودوافعها وأهدافها على تقبل الفرد كعضو بينها، أو رفضه ودرجة التفاعل معه إلى حد كبير على مدى تمسكه بمعايير الجماعة ومسايرته لها، من خلال السلوك المتوقع منه في المواقف الاجتماعية. وفي هذا الصدد يرى (الذويبي) أن (( التفاعل الاجتماعي يشير إلى السلوك الذي يحدث بشكل بشكل

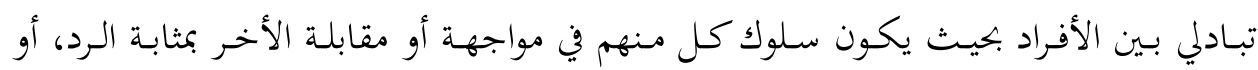
الاستجابة، بذلك يكون لاستمرارية الحياة الاجتماعية ارتباط وثيق باستمرارية الأفراد، في عملية التفاعل الاجتماعي في إطار منظومة العلاقات، والمواقف والتوقعات، والقيم. وبمعنى أعم في إطار 
الثقافة السائدة في المجتمع، ومنظومة الرموز والمفاهيم اللغوية المستخدمة )). (الذويبي، 1998،

ولما كانت المجتمعات البشرية ترتبط بعلاقات اجتماعية فيما بينها تحدد نمط العمليات

الاجتماعية، إذا كانت هذه العمليات مجمَعة كالتعاون والتآخي والتآزر والتوافق... أو عمليات مفرقة كالصراع والإكراه والإجبار والغيبية ... تتسم بالتغير الاجتماعي فإن هذه العمليات أيضا

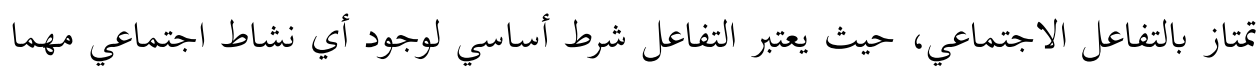
كانت طبيعة العمليات الاجتماعية ولذا فجميع العمليات الاجتماعية بغض النظر عن حجم الجماعة تعتبر شكلاً من أشكال التفاعل الاجتماعي.

ويعد التفاعل الاجتماعي أمرا حيويا للفرد والجماعة، إذ يصعب بل بلهي يستحيل تصور استمرار الجماعة الاجتماعية بدون تفاعل، فالأفراد والجماعات ترتبط فيما بينها بأساليب

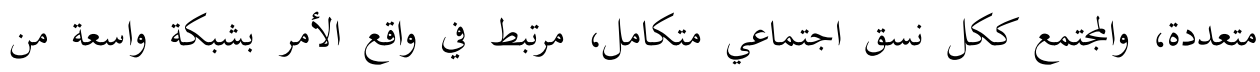
العلاقات الاجتماعية المبنية على التفاعل بين أعضائه. الأدوار والعلاقات الاجتماعية داخل الأسرة:

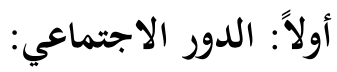

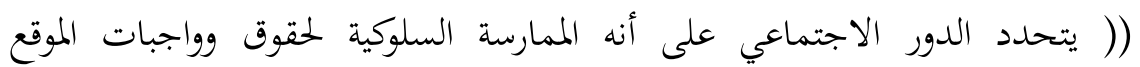

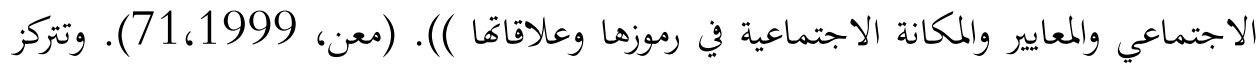
مفاهيم الدور والمكانة في قلب البناء الاجتماعي، ويستخدم مفهوم الدور بمعنيين مختلفين، المعنى

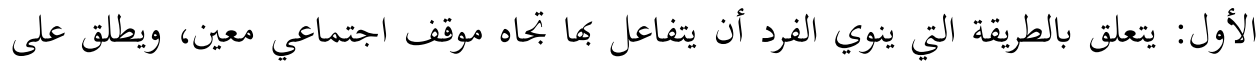
هذا النمط الدور الفردي أو الشخصي المتبادل، وعلماء الاجتماع وكذلك علك بلماء

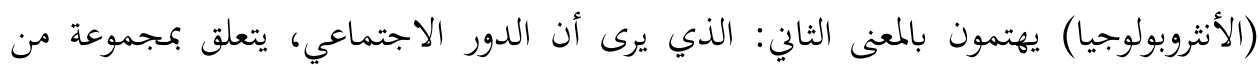
التوقعات أو أنواع السلوك المرتبطة بوضع معين في أي نظام اجتماعي، ويستخدم المفهوم عموما ليشير إلى السلوك المتوقع لشغل مكانة أو وضع اجتماعي. 
(ويقصد بالمكانة الاجتماعية وضع الفرد ضمن بناء اجتماعي يتحدد اجتماعيا وترتبط به النزعات وواجبات تقابلها حقوق وامتيازات، كما يرتبط بكل مكانة نمط من السلوك المتوقع، هذا ويمثل الدور الاجتماعي الذي يتضمن بالإضافة إلى السلوك المتوقع من الفرد الذي يشغل

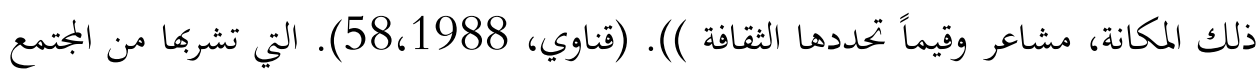

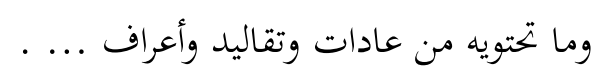

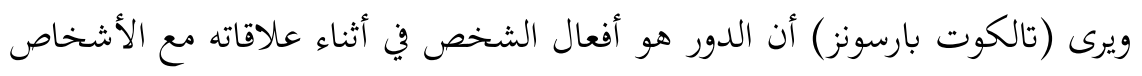

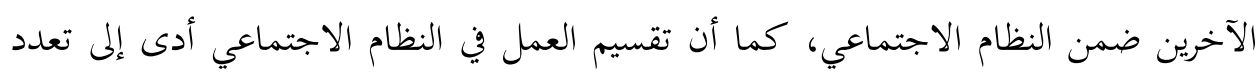

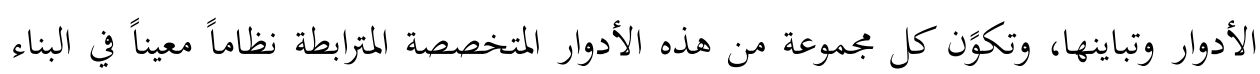
الاجتماعي، كما تكون مرتبطة وظيفيا وذات أهداف مشتركة.

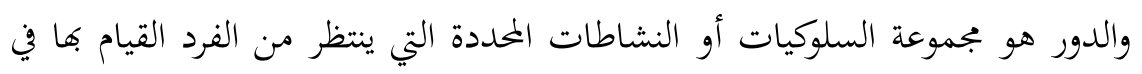

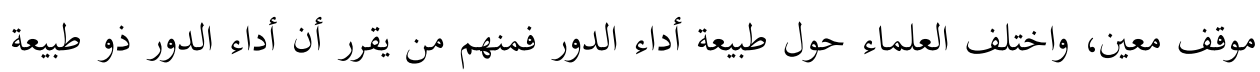

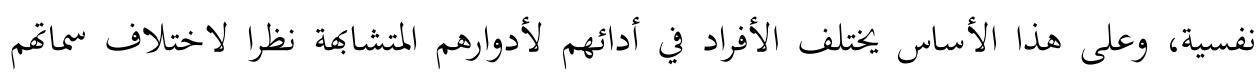

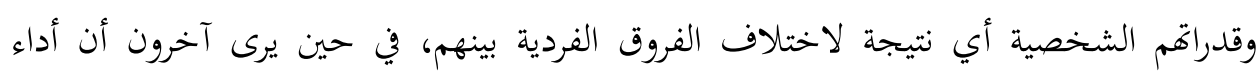

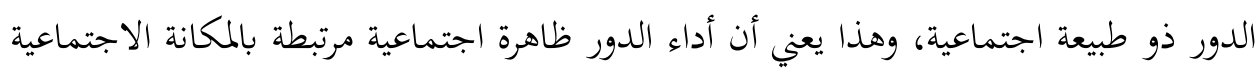

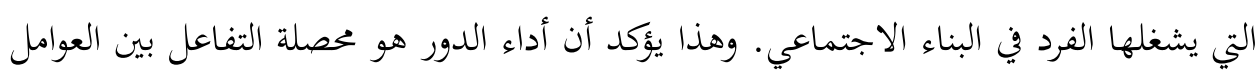
النفسية والعوامل الاجتماعية في المواقف الاجتماعية.

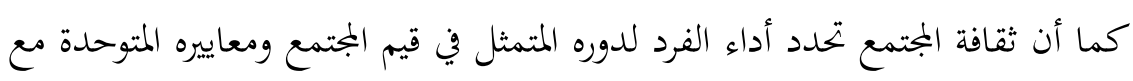

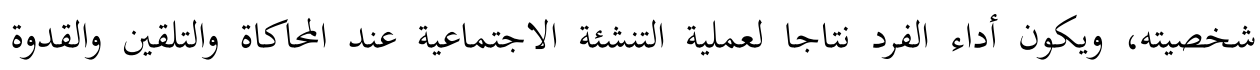

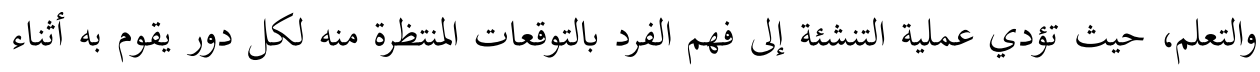
حياته بما تتطلبه مجريات حياته اليومية عن طريق التفاعل مع الآخرين.

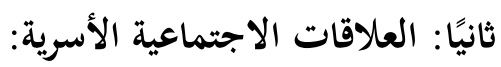

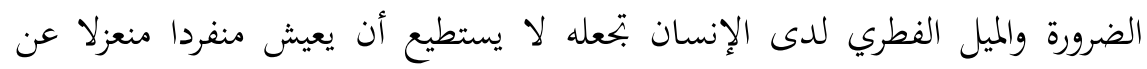

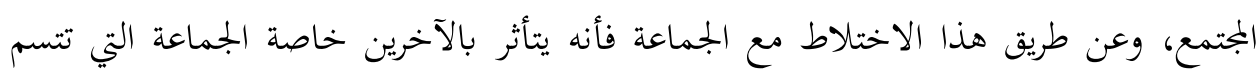


بخصائص الجماعة الأولية مثل الأسرة، كما أنه لا يستطيع أن يعيش منفردا بعيدا عن الظروف





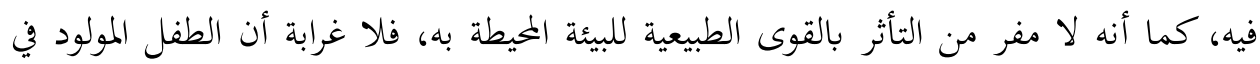

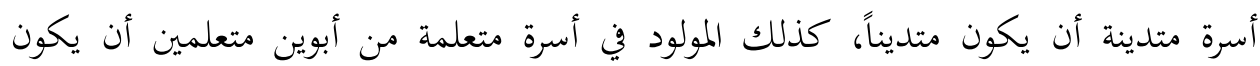



فالأسرة مسؤولة عن نسج خيوط أعضائها، فالاتحاهات التي في رؤوس الأبناء إنما

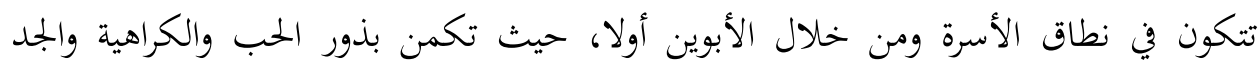

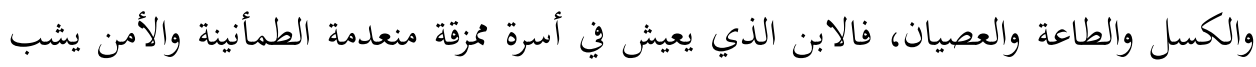

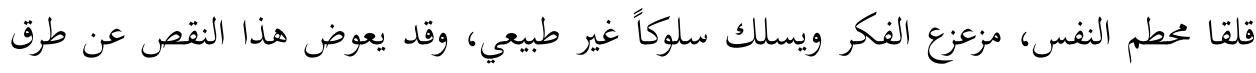

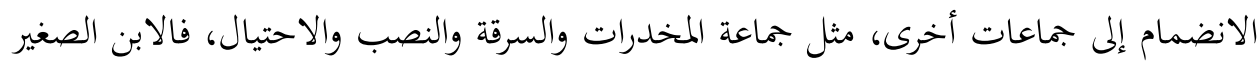

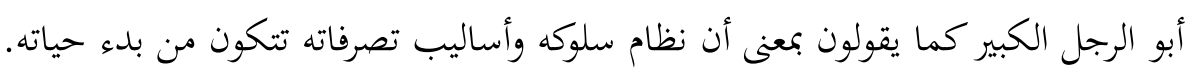
ويذكر علماء مدرسة التحليل النفسي أن خصائص الشخصية تتكون في السنوات نسات

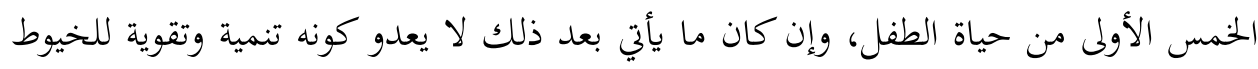
الرئيسية التي تنسجها الأسرة والبيئة. فلغة الحوار والتفاهم يؤدي إلى تماسك الأسرة، ويهيئ جوا لئس يساعد الأبناء على الوصول إلى شخصية متكاملة، وتؤدي إلى إشباع حاجاتم إلى الأمن

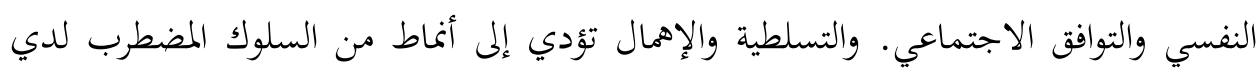
الأبناء كالغيرة والخوف وعدم الاتزان في تكوين علاقات مع الآخرين. ( (ويقصد بالعلاقات الأسرية تلك العلاقات التي تقوم بين أدوار الأب والأم والأبناء

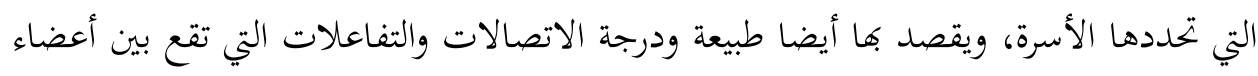
الأسرة الذين يقيمون في منزل واحد، ومن هذه العلاقة التي تقع بين الأب والأم وبين الآباء

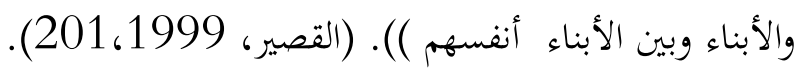


وتعتبر الأسرة بجتمعا صغيرا، وفي هذا المجتمع نجد ثلاث مجموعات من العلاقات

الاجتماعية الأساسية، وكل منها ذات طابع متميز في تداخلها و تأثيراتها المتبادلة:

\section{1 العلاقة الاجتماعية بين الزوج والزوجة:}

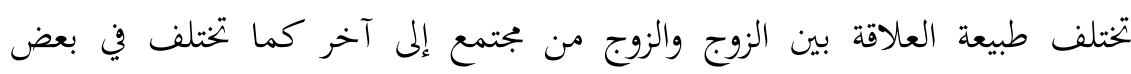
الأحيان من أسرة إلى أخرى في المجتمع نفسه. ففي الأسرة التقليدية يكون الزوج هو الآمر الناهي، لزوجته، وتكون الزوجة التابعة له تبعية كاملة، وهو المسؤول عن اتخاذ القرارات المتعلقة بشئون الأسرة، والأب يجد أساساً لسلطته هذه داخل الأسرة مستنداً إلى مركزه في العملية الإنتاجية وملكيته لوسائل الإنتاج، ودوره الرئيسي في العمل وفي توفير الاحتياجات الأساسية لحياة أفراد أسرته.

وكثيرا ما تكون علاقة الزوجة بزوجها علاقة طاعة وخضوع وتبعية مطلقة استنادا إلى أسباب ثقافية نشأة عليها المرأة في تفضيل الذكور عن الإناث، أو أسباب اجتماعية بتعل المرأة (الزوجة) في موقف دوبي في بيئة الأسرة التقليدية، أو بالاعتقاد بأن النساء لا يصلحن للقيام بالمهمات الخطيرة وتحمل المسؤولية التي تقرر مستقبل الأسرة، أو أسباب اقتصادية تتعلق بتقسيم العمل ودور المرأة الإنتاجي، لهذا اقتصرت مهمة الزوجة على البقاء في المنزل للقيام بالواجبات المنزلية كرعاية الأبناء الصغار وشؤون تدبير المنزل. وبانتقال المجتمع من المجتمع التقليدي إلى المجتمع الحديث والأخذ بسمات المجتمع المتحضر فإن الأسرة هي الأخرى تنتقل من نمط الأسرة التقليدي الممتدة ذات الحجم الكبير، والتي تضم الأجداد والأحفاد التي تكون فيها السلطة لكبار السن سواء أكان الأب الاجتماعي أم الزوج، إلى النمط الحديث النووي ذات الحجم الصغير والتي تتكون من الزوج والزوجة والأبناء الصغار غير المتزوجين، حيث تتغير وتتبدل طبيعة العلاقة الزوجية بين الزوج والزوجة، إلى التغاهم وتبادل الرأي والمشاركة في اتخاذ القرارات الأسرية، حيث يقوم الزوج باستشارة زوجته في الأمور المتعلقة بشؤون الأسرة والأبناء ومستقبلهم، كما يقوم بمساعدة زوجته في بعض الأعمال المنزلية، 
كما تتحمل الزوجة المسؤولية في حال غياب الزوج كذلك المساهمة في نفقات الأسرة نتيجة تعلمها وخروجها إلى الأعمال خارج المنزل.

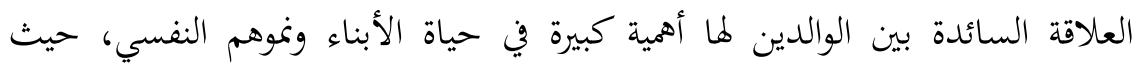

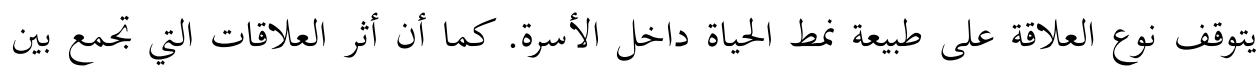

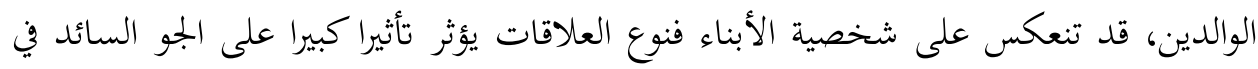

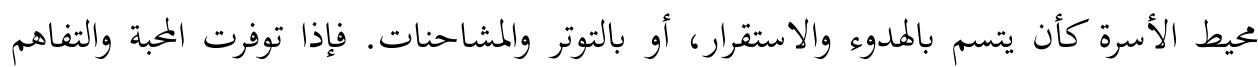

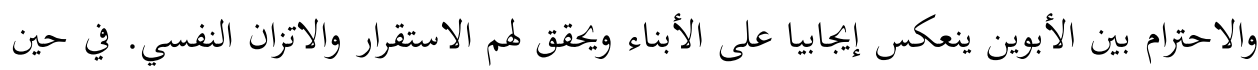

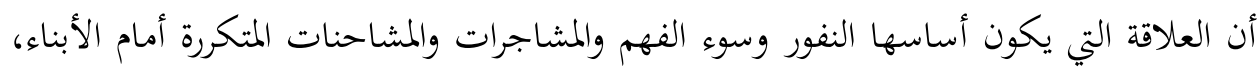
فغالبا ما تجعل لديهم مشاعر الضيق والتوتر وأنماط سلوكية مضطربة. وقد أكد كثير من العلماء كما ورد عن سهير كامل أحمد (( أن الأسرة المضطربة تنتج

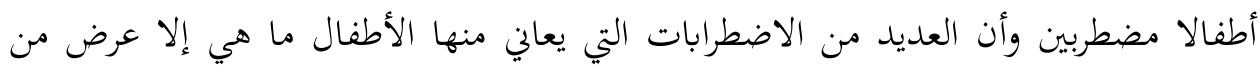
أعراض اضطراب الأسرة. ولذلك فإن طبيعة العلاقة بين الوالدين التي تتسم بالوفاق السَّوِي تؤدي إلى إشباع حاجة الطفل إلى الآمن النفسي والتوافق الاجتماعي. بينما تؤدي العلاقة التي

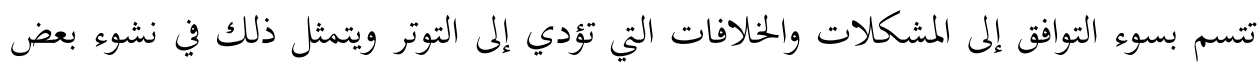
أنغاط السلوك المضطرب لدى الطفل كالغيرة والأنانية والخوف والميل إلى الشجار والذي مؤداه أن الآباء السعداء يخرجون أبناء سعداء )). (الحولي، 1984،315). وينعكس أثر العلاقات بين الوالدين على شخصية الأبناء، فكلما كانت العلاقة بين الوالدين يسودها الحب والتفاهم والانسجام والتعاون، أدى ذلك إلى جو أسري يساعد على نمو شخصية الأبناء المتزنة، بينما تؤدي الملافات والتشاحن والتشاجر بين الوالدين، إلى نمو نفسي غير سليم. فالعلاقات السوية بين الوالدين تؤهل الابن إلى أن يكون قادرا على التوافق السوي،

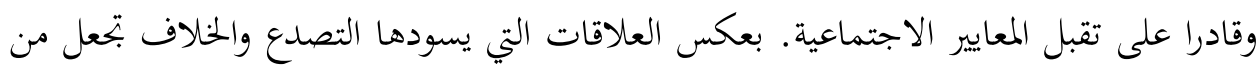
الصعب على الأبناء تكوين علاقات سوية مستقبلا مع الشعور بالقلق وانعدام الأمن. 


\section{2. العلاقة الاجتماعية بين الآباء والأبناء:}

يعد نسق الأسرة هو المحيط المباشر الذي يحدث فيه التفاعل بين الآباء والأبناء، وذلك عن طريق أساليب معاملة الو الدين التي يتلقاها الأبناء أثناء تنشئتهم الاجتماعية. فالعلاقات التي يوفرها الآباء داخل البيت، المنسجمة والخالية من التفرقة والتفضيل بين الأبناء الذكور سواء أكان للترتيب الميلادي أم تفضيل أحدهم عن الأخر بسبب المساهمة في دخل الأسرة، أو لزوجة المباء


تمويل وعزة للأسرة، كل هذه العوامل وغيرها تؤدي إلى النمو السوي. والمناخ الأسرى الذي يتسم الإباء بإشباع الحاجات النفسية وبخاصة الحب والأمن، واحترام حقوق الآخرين والتعاون والمنافسة

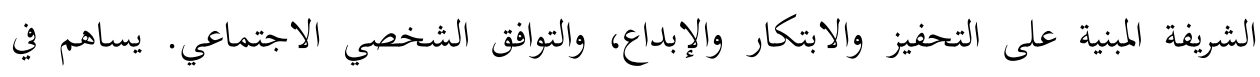
تكوين الشخصية المتزنة لدى الأبناء.

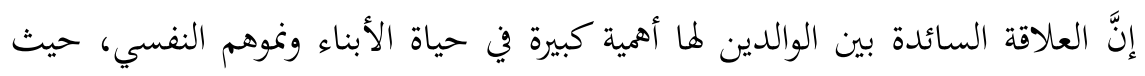
يتوقف نوع العلاقة على طبيعة نمط الحياة داخل الأسرة. كما أن أثر العلاقات التي بتمع بين الوالدين، قد تنعكس على شخصية الأبناء، فنوع العلاقات يؤثر تأثيرا كبيرا على الجو السائد في محيط الأسرة كأن يتسم بالهدوء والاستقرار، أو بالتوتر والمشاحنات. فادا توفرت المحبة والتفاهم

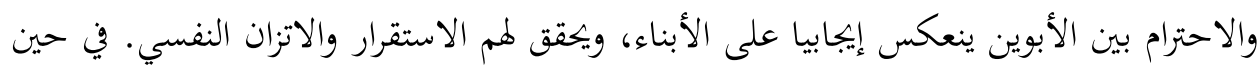

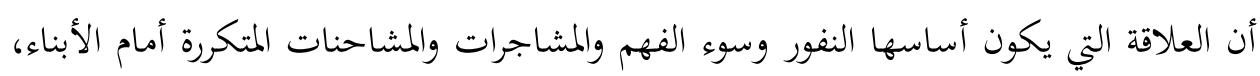
فغالبا ما تجعل لديهم مشاعر الضيق والتوتر وأنماط سلوكية مضطربة.

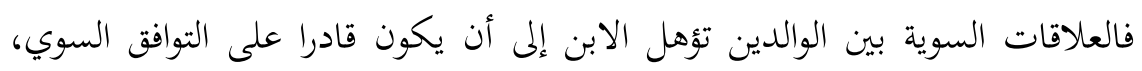
وقادرا على تقبل المعايير الاجتماعية. بعكس العلاقات التي يسودها التصدع والخلاف بتعل من الصعب على الأبناء تكوين علاقات سوية مستقبلا مع الشعور بالقلق وانعدام الأمن (( كما أن انشغال الوالدين عن أبنائهما جلٍ الأوقات وعدم تخصيص أوقات معينة يقضوها مع أبنائهم وعدم مشاركتهم في مناقشة قضايا الأسرة وانعدام التوجيه السليم، يمهد لإنحراف الأبناء كرد فعل لهذه العلاقة السلبية )). (التير، 1995، 90). 


\section{3. العلاقة بين الأبناء أنفسهم:}

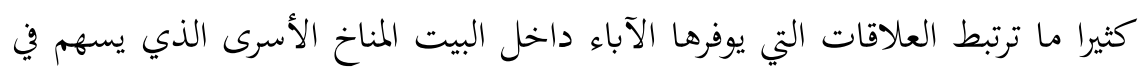



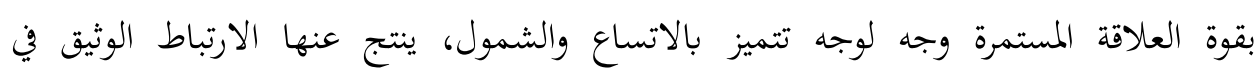
العمليات الاتصالية والتي تتضمن معظم مناحي مجريات الحياة اليومية، تتسم بالصراحة والوضوح

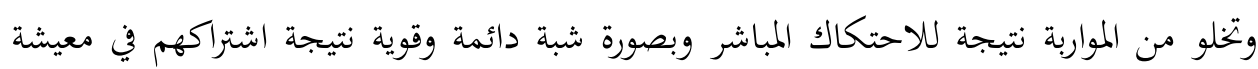
واحدة، مما يترتب عليها التزامات وتقدير حقوق وواجبات الآخرين.

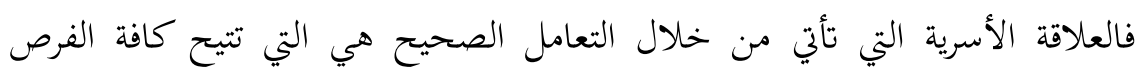
الممكنة في نطاق الأسرة للأبناء التعبير عن أذواقهم ورغباقم ووجهات نظرهم في حدود اللياقة

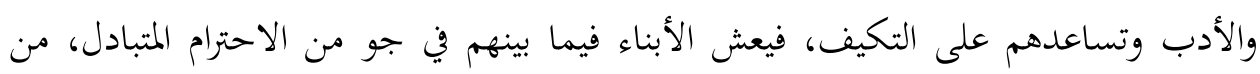
خلال بيئتهم الاجتماعية الصالحة للنمو الاجتماعي السليم. فمعرفة الآباء بالثقافة العامة للتربية الصحيحة في حسن التعامل مع الأبناء من العوامل الأساسية في تحديد سلوك الأبناء، ولما تأثيرها الظاهر في تصرفات الأبناء وخاصة المراهقين منهم، فإن مرحلتي الطفولة والصبا تتشكل فيهما المقومات الأساسية للشخصية، فالبيت المتسم بالمدوء والسكينة المنتظم في سلوكه العام، الذي لا تغيب عنه المسؤولية الأبوية أو تضطرب، والذي يستقيم فيه التعامل على نمط صحيح فتسوده المودة والمحبة ويعيش فيه الأبناء حياة هادئة سوية تمكن الأبناء وخاصة المراهقين منهم على التغلب على مشاكلهم، أما إذا اضطرب سلوك الأبوين أو اضطرب أسلوب معاملتهما للأبناء أو فضل أحدهما أو كلاهما بعض الأبناء على بعض ذكورا أو إناثا، أو مال احدهما أو كلاهما إلى القسوة والعنف، أو مال أحدهما أو كلاهما إلى التدليل، أدت هذه الأساليب إلى كثرة المشاكل، تصعب سلامة الأبناء وخاصة المراهقين منهم من نتائجها السلبية. فإقامة علاقات المحبة والتآلف غير المباشرة وبدون تصدير أوامر ونواهي، وأتباع أسلوب التوجيه الملائم. 
( (الآباء مطالبون بالتعامل مع أبنائهم، وخاصة في مرحلة المراهقة على أساس الصداقة، أما الذين يرون في ذلك انتقاصاً من شخصيتهم كما أفم يجدون في استخدام الكلام الجارح وتقمص دور العصبية الشديدة إعزازا لمم وتكبيرهم أمام أبنائهم، في حين أن علماء الاجتماع

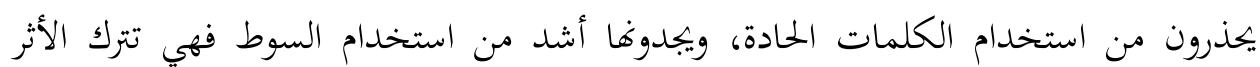
الكبير في نفسية البنت والولد )). (الخالدي، 2014، مركز الأبحاث العالمي).

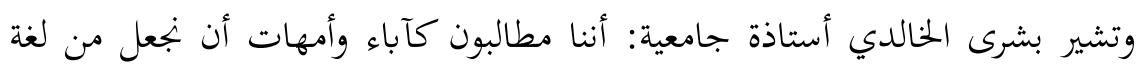
التفاهم والحوار الأساس الذي تقوم عليه علاقتنا بأبنائنا سواء في التربية أو في مناقشة أمور الحياة المختلفة وانطلاقاً من مبادئ ديننا الحنيف فإننا مطالبون بالتعامل مع أبنائنا وخاصة في مرحلة

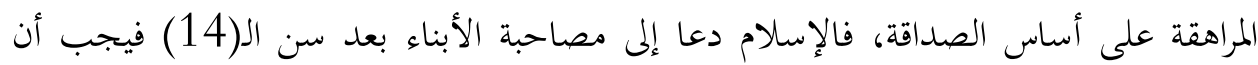
نحاول قدر الإمكان تقريب المسافات بيننا وبينهم، حتى وإن تطلب الأمر النزول إلى مستوى الأبناء، وإزالة الحواجز فيما بيننا وبينهم. إن الأب القادر على جعل الأسرة من بجرّد بتمّع كمّيّي إلى مكان يتبادل فيه الجمبيع الحبرات والتصوّرات والآراء، وتحقّق قدراً لا بأس به من الشعور بادئ بالمسؤولية الجماعية التضامنية، وتوزيع المهام والتكاليف، وتقسيم الأعمال والوظائف مهمّة سهلة ومقبولة من الجميع الذين

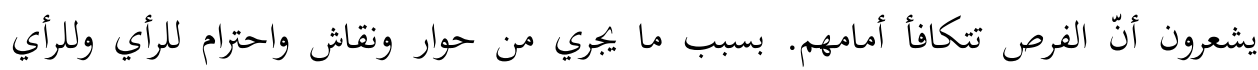

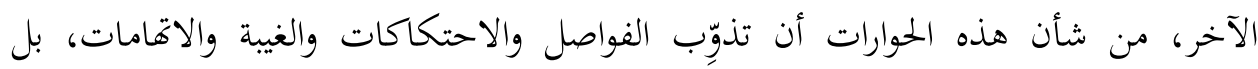
وتعكس الصورة إلى التوافق والانسجام والتجانس بما توفِّره من أجواء التدريب على النقد الذاتي والاجتماعي. إن قدرة الأب وهو رب الأسرة، ترجيح كفّة الحاجات الأساسية على الرغبات العابرة، وأن تكون له القدرة على تقدير الأولويات، ملمّاً بتطور العصر وإيقاعه والظروف المتغيّرة، لأنه

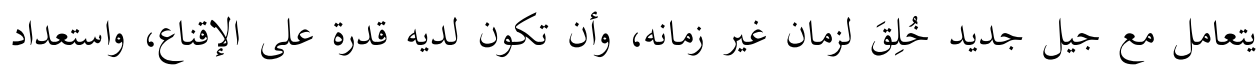
للاقتناع. وأن يكون منفتحاً في تقبّل جميع الآراء حتى تلك التي تبدو غير معقولة، وأن يناقشها

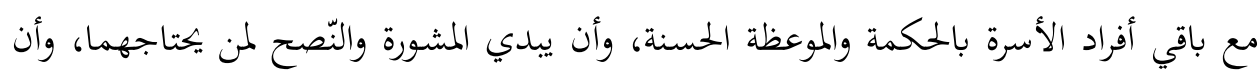


يفضّ النزاع بين الإخوة كحكم عدل. وأن يتمّّع بصفة الآراء التي قد لا يحسن الأبناء تقديمها،

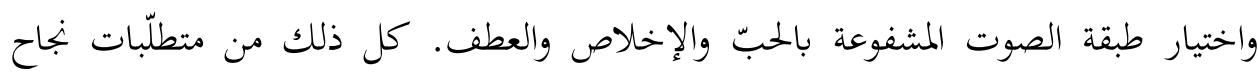

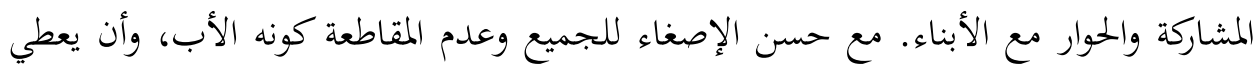

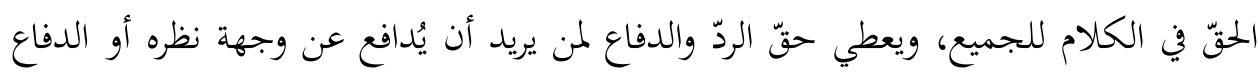

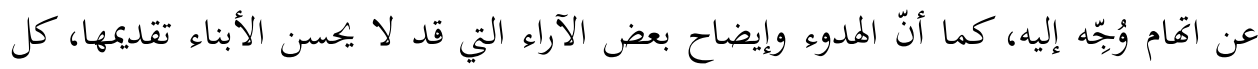
ذلك من متطلّبات نجاح المشاركة والحوار مع الأبناء.

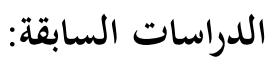

من بين الدراسات العالمية التي اهتمت بهذا الشأن الدراسة التي قام بها (باروخ (Baruch

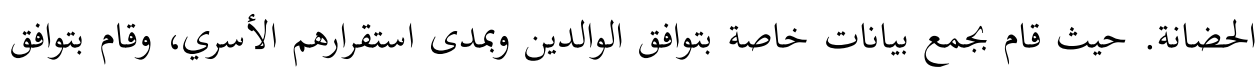

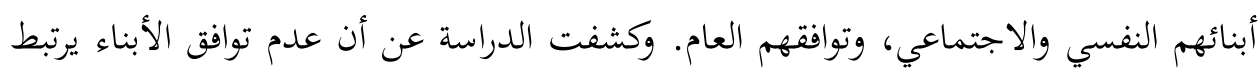

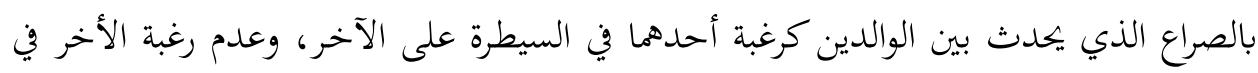

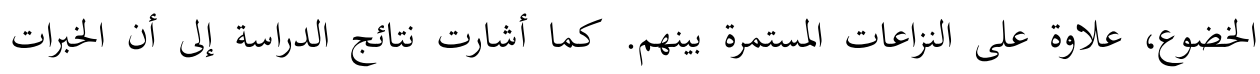

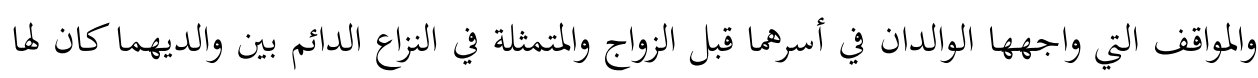

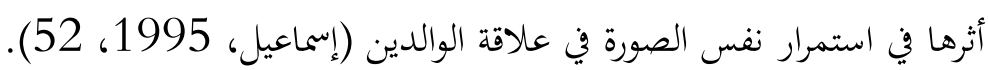

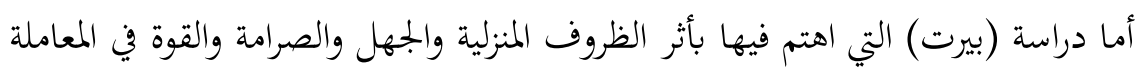

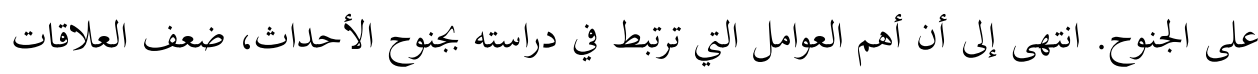

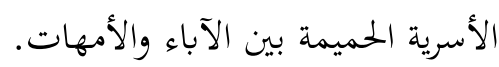

وعلى ذلك فالعلاقات الوالدية الحميمة الودودة المتسمة بالحب والتفاهم وانعدام أو قلة الخلافات والمشاجرات، والأسرة المنسجمة المتعاونة هي بيئة صالحة لنمو الأبناء من الناحية

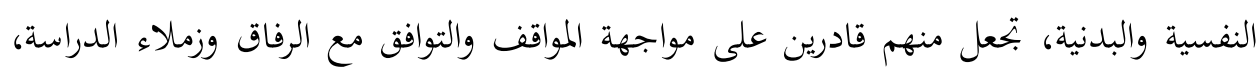
قادرين على التحصيل الجيد والتفوق والاعتماد والثقة بالنفس. 
ومن الدراسات العربية دراسة (مُحَّمَ بيومي خليل) التغيرات المعاصرة وأثرها على المناخ الأسري للأسرة المصرية سنة 2000م، دراسة منشورة على عينة قوامها (200) مراهق ومراهقة من طلاب المدارس الثانوية بمحافظة الشرقية منهم 120 مراهق و80 مراهقة. حيث كشف درة أن التغيرات المعاصرة أدت بالمجتمع المصري من حيث درجة التحضر والمشكلات السكانية والاجتماعية والاقتصادية إلى تغيرات جديدة، ترتب عليها: استغراق الآباء في العمل طوال اليوم،



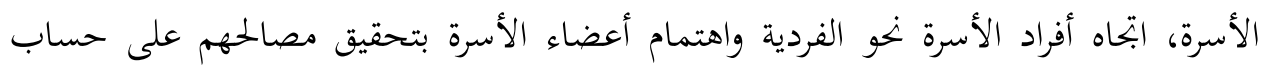
الآخرين، اتساع الفوارق والهوة بين الإباء والأبناء.

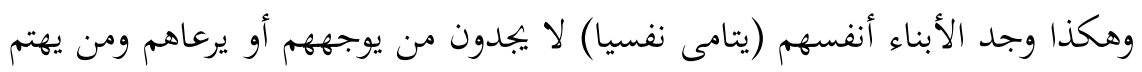

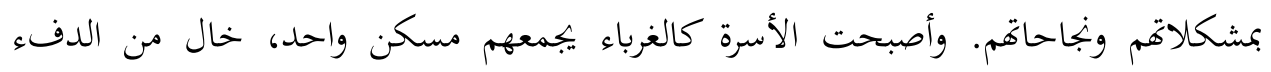
العاطفي والانسجام، وأصبح الأبناء محرومين من حديث يجمعهم والآباء حول مستقبلهم وطموحاتم. وقد استخدم الباحث، مقياس المناخ الأسري: شعور أعضاء الأسرة بالأمان، التضحية

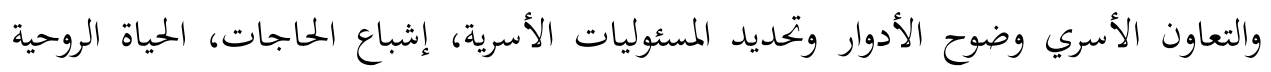

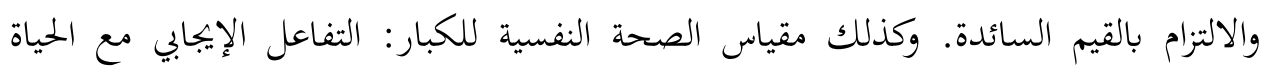

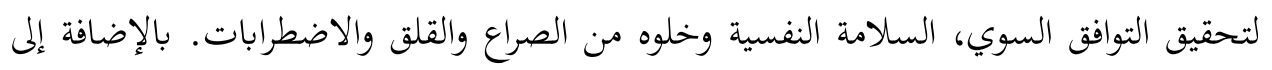

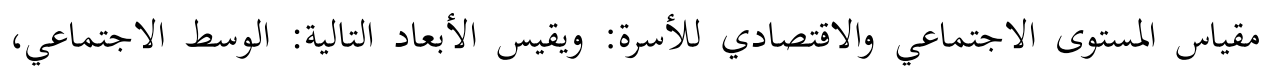
مستوى تعليم الوالدين، المستوى المهني للوالدين، مستوى المعيشة.

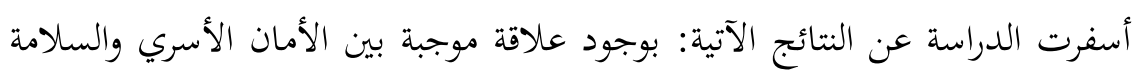

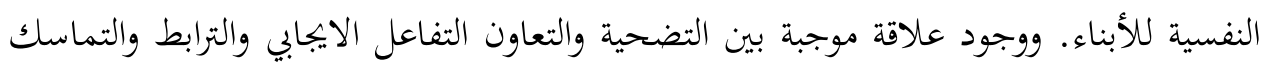
الأسري للأبناء. كذلك وضوح الأدوار ووجود ادوار واضحة لكل من الآباء والأبناء بحسب ولبن

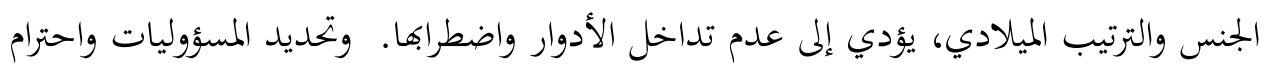
ادوار الآخرين. كما كشفت عن وجود فروق دالة بين متوسطي درجات ذوي المستوى 
(الاجتماعي-الاقتصادي) المرتفع، وذوي المستوى (الاجتماعي-الاقتصادي) المنخفض في: وضوح الأدوار وتحديد المسؤوليات لصالح ذوي المستوى (الاجتماعي-الاقتصادي) المرتفع في الوضع الأفضل، كذلك أوضحت بأن توجد فروق دالة بين متوسطي درجات البنين والبنات في التفاعل الايجابي مع الحياة لصالح البنين في الوضع الأفضل؛ لأن التقاليد والأعراف الاجتماعية

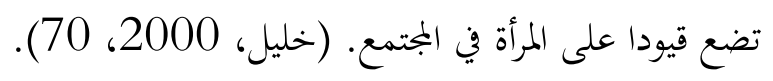
ومن الدراسات المحلية دراسة فائزة عبد الله البشتي الموسومة بعلاقة العوامل الديموغرافية والاجتماعية والاقتصادية بأساليب التنشئة الاجتماعية الأسرية 2003. والتي هدفت إلى معردي الى معرفة أثر علاقة العوامل الديموغرافية والاجتماعية والاقتصادية بأساليب التنشئة الأسرية في الأسرة

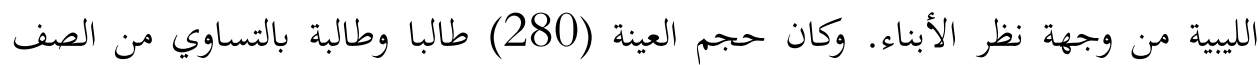
التاسع تعليم أساسي والصف الثالث ثانوي بقسميه الأدبي والعلمي في مدراس مدينة الزاوية.

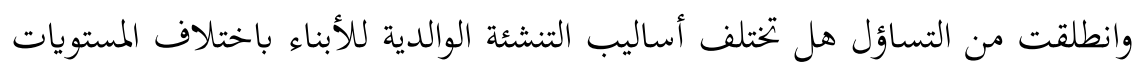
الاقتصادية والاجتماعية؟ كذلك هل تختلف أساليب معاملة الوالدين في التنشئة الاجتماعية لأبنائهم من الجنسين (ذكورا وإناثا)؟

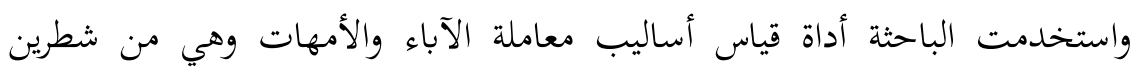
متماثلين تماما، يقيس الأول معاملة الآباء ويقيس الثاني أساليب معاملة الأمهات، ويتكون كل

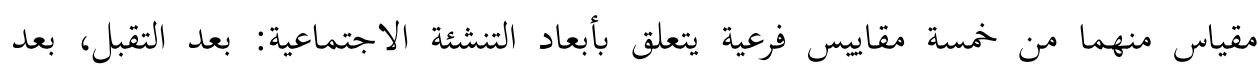
الرفض، بعد التسامح، بعد التشدد، بعد الاستقلال، بعد التبعية والتحكم.

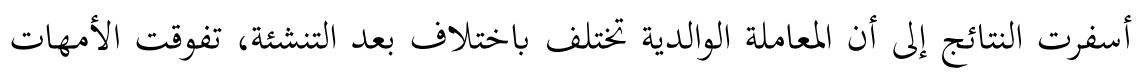
على الآباء في معظم أبعاد التنشئة الاجتماعية على وجه العموم. فكانت الأمهات أكثر تسامحا وتقبلا ورفضا وتشددا في تنشئهن من الآباء، في حين كان الآباء أكثر من الأمهات منحا

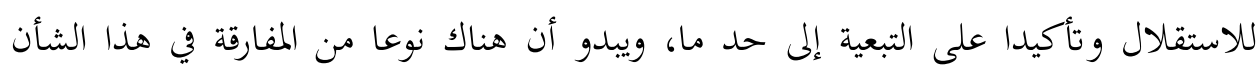
اقتضته طبيعة الظروف المحيطة، وبرهنت نتائج الدراسة على آن الدخل والتعليم يؤديان دورا مهما في التأثير في أبعاد التنشئة الاجتماعية وعلاقتها بالتفاعل الاجتماعي الأسري. 


\section{بعض النظريات المفسرة للتفاعل الأسري والقيام بالأدوار داخل الأسرة:}

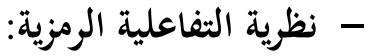

نظرية التفاعلية الرمزية أكثر الابحاهات استخداما في بجال علم اجتماع الأسرة، وهي تركز على دراسة العلاقات بين الزوج والزوجة والآباء والأبناء كشخصيات متفاعلة. وإن الشخصية ليست كيانا ثابتا داخل الأسرة، بل هي مفهوم دينامي معاث ومتغير. وتفسير الفرد للحياة الاجتماعية، وتعتبر التفاعل الاجتماعي يعتمد على النشاط العقلي لممارسة الضبط لمبط الرمزي على مختلف أنواع السلوك. ويؤدي التفاعل الاجتماعي إلى ظهور العلاقات المتبادلة في الحياة الاجتماعية.

() يعد التفاعل الاجتماعي أو الرمزي نموذجا هاما من العلاقات التي تفسر سلوك الإنسان، حيث يتميز الإنسان بالقدرة على الإدراك العقلي الذي يمكنه من معرفة موضوعات البيئية المحيطة به والوسائل التي يمكنه من خلالما تحقيق أهدافه، ومن خلال النشاط العقلي استطاع الإنسان ممارسة الضبط الرمزي على سلوكه. فأخذ يعرض مشاعره وآراءه بشكل واضح، في الماضي والحاضر والمستقبل فخبرته هي التي تقرر الفعل الذي يفعله والذي من خلاله يتم الاتصال بالوحدات الأخرى في النسق الاجتماعي، متخدما في ذلك بعض الأساليب كالرموز ومطبقا بعض المعايير التي توجه سلوكه بحاه الآخرين )). (فرج 1998، 93).

يرى أصحاب هذا الاتحاه، أن التفاعل الرمزي هو تلك العملية التي ترتبط فيها أفكار الفرد بأفكار الآخرين، والتي من خلالها يفسر الأفراد حاجاتم ورغباهم وأهدافهم وميوهم. ويشير التفاعل الاجتماعي أو الرمزي إلى (( العلاقات التي يمققها الأفراد من خلال قدرقم الفسيولوجية وككائنات عضوية فاعلة يؤثر كل منها في الأخر، وإفم ينمون ويتطورن سويا، هذا التأثير المتبادل يقوم على أساس مكانتهم ككائنات عضوية واجتماعية، ويؤكد التفاعل الرمزي على مظاهر التفاعل النفسي )). (غيث، 1990، 252). 


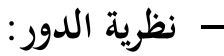

تعتبر نظرية الدور من النظريات المهمة في دراسة الأسرة خاصة عندما يكون التركيز منصبا على العمليات الداخلية في الأسرة مثل التنشئة الاجتماعية والعلاقات الأسرية، وفقا للمحددات الثقافية، ومدى التزام الفرد أو عجزه عن أدائها. وتتركز مفاهيم الدور والمكانة في قلب البناء الاجتماعي، ويستخدم مفهوم الدور (المأخوذ من المسرح) للدلالة على أنه جزء أو نموذج من السلوك المتوقع من شخص يقوم بأدائه في البناء الاجتماعي عالي التفاعل، حيث يكون هناك مشهد يحتوي على الأدوار المخصصة

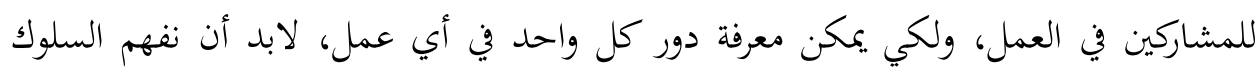
المتوقع أو المطلوب في موقف معين.

كما يستخدم مفهوم الدور بمعنيين مختلفين: المعنى الأول، يتعلق بالطريقة التي ينوي موفي

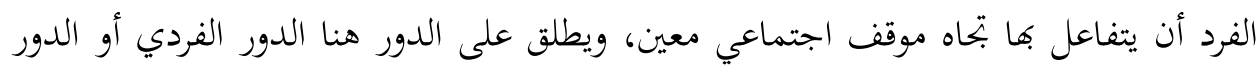

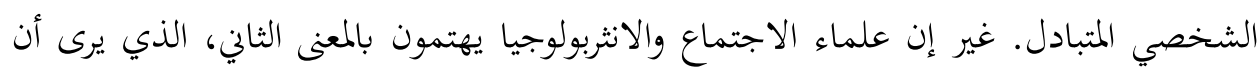
الدور الاجتماعي مجموعة من التوقعات أو أنواع السلوك المرتبطة بوضع معين في أي نظام اجتماعي، ويستخدم المفهوم عموما ليشير إلى السلوك المتوقع لشغل مكانة أو وضع اجتماعي.

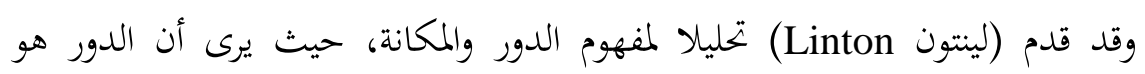

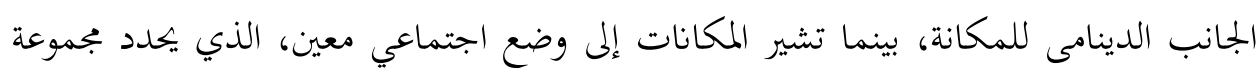
الحقوق والواجبات والالتزامات، فالدور يقتضي الممارسة خارج المكانة، وتوقعات الدور في تيني السلوك المنتظر مرتبط بالمكانة التي يشغلها الفرد.

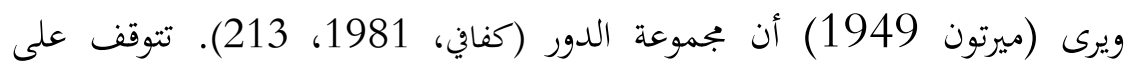

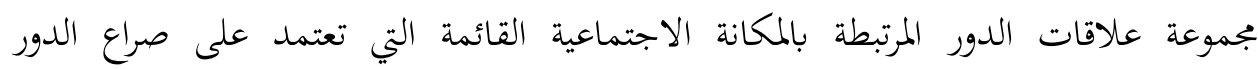
وتوقعاته، حيث تركز نظرية الدور الاجتماعي في تفسير عمليه التنشئة الاجتماعية على مفهومين

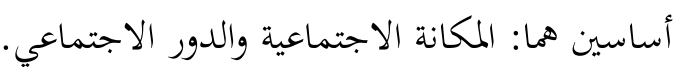


(( ويقصد بالمكانة الاجتماعية وضع الفرد ضمن بناء اجتماعي يتحدد اجتماعيا ويرتبط به النزعات، وواجبات تقابلها حقوق وامتيازات كما يربط بكل مكانة نمط من السلوك المتوقع، وهذا يمثل الدور الاجتماعي الذي يتضمن بالإضافة إلى السلوك المتوقع من الفرد الذي يشغل ذلك المكانة، مشاعر وقيما تحددها الثقافة )). (إسماعيل، 1993، 62). إن الامتيازات التي يحصل عليها الفرد تنشأ من الحقوق مع وضع الواجبات والالتزامات في الاعتبار، فالحقوق والواجبات جانبان أو وجهان لعملة واحدة بين فردين، لذا كان التعليم الاجتماعي في أي مجتمع، إنما هو تعليم الفرد واجباته والتزاماته بتاه الآخرين. وتؤكد كل من نظرية التفاعلية الرمزية ونظرية الدور على اعتبار السلوك أدواراً يؤديها الفرد. كما تعرف عملية التنشئة الاجتماعية في ضوء هذه النظرية. بالعملية التي يتعلم فيها الفرد أن يسلك بما يتفق مع ما يتطلبه أدوار اجتماعية معينة، ومع ما يتوقعه أعضاء الجماعة من سلوك وتصرفات ممن يقوم بهذه الأدوار التي تتراوح بين دور الابن أو البنت، ودور الزوج أو الزوجة، ودور الأب أو الأم (قناوي، 1988، 58). يعد الدور الاجتماعي المظهر الأساسي للتفاعل الاجتماعي، والذي يفهم من خلاله عمليات توقع سلوك الآخرين ومن خلال رؤية الفرد لدوره، والأدوار المسندة إلى الآخرين. أي أن المكانة الاجتماعية ما كانت لتوجد لولا وجود الأخر سواء كان فردا، أو جماعة، أو مجتمعا، وكل فرد ينتمي إلى مكانة معينة تحدد علاقته بغيره من الأفراد ومع المكانات الأخرى، وتحدد حقوقه وواجباته داخل التنظيم الاجتماعي، تلك الحقوق والواجبات ترمز إلى الأدوار التي يؤديها الفرد في المجتمع، فالمكانة إذن هي التي تحدد دور الفرد في المجتمع، وتتكون مكانة الفرد من عدد من الأدوار المرتبطة بالتوقعات الاجتماعية. 


\section{إجراءات الدراسة:}

نوع الدراسة: يمكن تصنيفها منهجيا على أها دراسة وصفية تحليلية، فالتركيز يتجه نحو

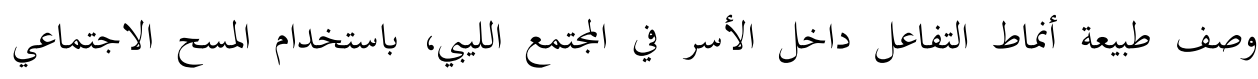
بالعينات.

عينة البحث وحجمها: تركزت وحدة الاهتمام والتحليل على عينة قوامها (240) مفردة من الطلاب مرحلة التعليم المتوسط، موزعين بالتساوي على ست (6) محلات بواقع مدرستين من كل محلة بعدد (20) مفردة، وفقا لمتغير النوع (ذكور -إناث) ثم اختيارهم بالطريقة العشوائية من مدينة مصراتة حسب التصنيف الإداري للمحلات (شهداء الرميلة، ذات الرمال، الزورق، رأس الطوبة، زاوية المحجوب، قصر احمد) ليعكس التباين الاجتماعي والثقافي بين إفراد العينة وأسرهم مما يجعل هذه الطريقة أكثر اقترابا من الواقع الفعلي. أسلوب جمع البيانات: لجأ الباحث إلى استخدام أسلوب المعاينة لجمع البيانات لاستيفاء المعلومات حول موضوع الاهتمام، لما يوفره هذا النوع (من المسوح) من الوقت والجهه والتكاليف.

أداة جمع البيانات: استخدم الباحث استمارة المقابلة المقننة وذلك بالاتصال الشخصي القائم على التفاعل وجها لوجه مع المبحوث، وقد طورت المقابلة من خلال أسئلة أعدت سلفا قبل بداية المقابلة وفق معايير وشروط محددة، تمثلت في جانبين، الجانب الأول المعلومات الأولية تتعلق بالنوع والعمر والسكن وملائمته، والدخل وكفايته والخلفية الحضارية، والجانب الثاني فقد تمثل في بعدين طبيعة العلاقة ودرجة التفاعل داخل الأسرة. الأساليب الإحصائية المستخدمة: استخدم النسب المئوية للكشف عن وجود تباين في خصائص المتغير، المتوسط الحسابي المرجح والوزن المئوي، لبيان أهمية فقرات المقاييس. 


\section{تحليل وعرض النتائج وتفسيرها:}

\section{الأهمية النسبية لمقياس قواعد معايير التفاعل لطبيعة العلاقة الاجتماعية داخل الأسرة}

جدول يبين توزيع أفراد العينة والوسط المرجح والوزن المئوي حسب التدرج الخماسي لطبيعة التفاعل الاجتماعي

\begin{tabular}{|c|c|c|c|c|c|c|c|c|c|c|c|c|}
\hline \multirow{2}{*}{ 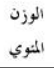 } & \multirow{2}{*}{ المرجع الوسط } & \multicolumn{2}{|c|}{ بدرجة قليلة جدا } & \multicolumn{2}{|c|}{ بدرجة قليلة } & \multicolumn{2}{|c|}{ بلمرجة لحد ما } & \multicolumn{2}{|c|}{ بلدرجة كبيرة } & \multicolumn{2}{|c|}{ بدرجة كيرة جدا } & \multirow{2}{*}{ الققرات } \\
\hline & & $\%$ & 3 & $\%$ & 3 & $\%$ & 3 & $\%$ & 3 & $\%$ & ك & \\
\hline 21.2 & 4.41 & 1.0 & 03 & 2.9 & 07 & 9.1 & 22 & 30.4 & 73 & 57.0 & 137 & 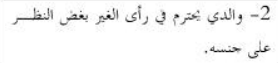 \\
\hline 21.1 & 4.39 & 1.6 & 04 & 3.3 & 08 & 3.0 & 07 & 38.0 & 91 & 54.1 & 130 & 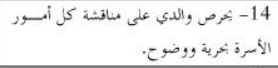 \\
\hline 21.0 & 4.38 & 2.1 & 05 & 2.1 & 05 & 3.7 & 09 & 39.6 & 95 & 52.5 & 126 & بخصه لخأولاده. والدي من وقته لبناته كالذي \\
\hline 21.0 & 4.37 & 0.8 & 02 & 1.6 & 04 & 4.6 & 11 & 40.0 & 96 & 53.0 & 127 &  \\
\hline 20.4 & 4.27 & 2.1 & 05 & 3.3 & 08 & 9.6 & 23 & 34.6 & 83 & 50.4 & 121 & قي حياة سعيدة. \\
\hline 20.0 & 4.25 & 3.7 & 09 & 4.2 & 10 & 7.1 & 17 & 33.3 & 80 & 51.7 & 124 & وتقدير ـيختر والدي أراء أخســراني بكسل ود \\
\hline 20.0 & 4.17 & 3.3 & 08 & 6.0 & 14 & 9.1 & 22 & 33.0 & 79 & 48.7 & 117 & 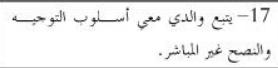 \\
\hline 20.0 & 4.16 & 4.2 & 10 & 5.1 & 12 & 11.2 & 27 & 33.3 & 80 & 46.2 & 111 & 8- ئشعر كل فرد منا بـالاعتزاز بالأســرة \\
\hline 19.8 & 4.14 & 4.2 & 10 & 5.8 & 14 & 10.8 & 26 & 34.1 & 82 & 45.0 & 108 & 9- أفراد الألثرة المبادلة والصدق أساس الثعامل بين \\
\hline 19.2 & 4.01 & 5.1 & 12 & 5.4 & 13 & 18.7 & 45 & 29.6 & 71 & 41.2 & 99 & 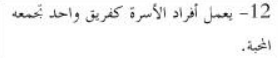 \\
\hline 19.2 & 4.02 & 1.6 & 04 & 4.2 & 10 & 22.1 & 53 & 34.1 & 82 & 38.0 & 91 &  \\
\hline 19.2 & 4.00 & 2.1 & 05 & 2.5 & 06 & 24.6 & 59 & 34.6 & 83 & 36.2 & 87 & 13-عيامل والدي أبناته كر جال ناجحين. \\
\hline 19.2 & 4.00 & 2.1 & 05 & 2.9 & 07 & 23.3 & 56 & 35.8 & 86 & 35.8 & 86 & 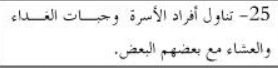 \\
\hline 18.6 & 3.88 & 5.1 & 12 & 8.3 & 20 & 19.6 & 47 & 27.0 & 65 & 40.0 & 96 & 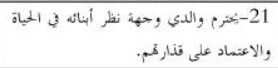 \\
\hline 13.7 & 2.87 & 4.1 & 10 & 9.2 & 22 & 20.4 & 49 & 27.9 & 67 & 38.4 & 92 & 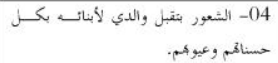 \\
\hline 10.1 & 2.21 & 39.1 & 94 & 27.5 & 66 & 21.0 & 50 & 7.1 & 17 & 5.4 & 13 & 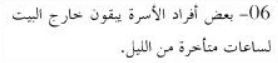 \\
\hline 9.3 & 1.94 & 48.3 & 116 & 24.6 & 59 & 16.2 & 39 & 6.2 & 15 & 4.6 & 11 & هم. 05- والدي يخطي ب حق الأسرة رغم حبه \\
\hline 7.8 & 1.65 & 57.1 & 137 & 23.7 & 57 & 15.4 & 37 & 3.7 & 09 & 0 & 0 & الأسرة. المسوريات غير عددة بــين أعضـاء \\
\hline 7.7 & 1.62 & 71.2 & 171 & 10.4 & 25 & 8.0 & 19 & 5.8 & 14 & 4.6 & 11 & 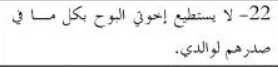 \\
\hline 7.5 & 1.47 & 79.1 & 190 & 8.0 & 19 & 4.6 & 11 & 4.1 & 10 & 4.1 & 10 & أهوأهم. -يتصرف الأبناء دون علم الأباء حسب \\
\hline 7.5 & 1.58 & 71.6 & 172 & 10.0 & 24 & 10.0 & 24 & 4.6 & 11 & 3.7 & 09 & حق، ويلغي دور غيره. \\
\hline 7.3 & 1.52 & 75.4 & 181 & 9.6 & 23 & 7.1 & 17 & 3.3 & 08 & 4.6 & 11 & 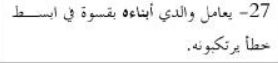 \\
\hline
\end{tabular}




\begin{tabular}{|c|c|c|c|c|c|c|c|c|c|c|c|c|}
\hline 7.0 & 1.42 & 77.5 & 186 & 10.8 & 26 & 5.4 & 13 & 3.7 & 09 & 2.5 & 06 & 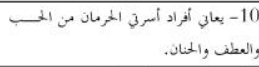 \\
\hline 6.9 & 1.44 & 78.8 & 189 & 8.7 & 21 & 5.4 & 13 & 3.7 & 09 & 3.3 & 08 & 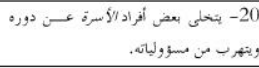 \\
\hline 6.7 & 1.41 & 77.1 & 185 & 11.2 & 27 & 6.7 & 16 & 2.9 & 07 & 2.1 & 05 & 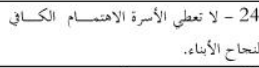 \\
\hline 6.6 & 1.38 & 78.8 & 189 & 9.6 & 23 & 6.2 & 15 & 5.0 & 12 & 0.4 & 01 & 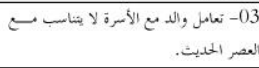 \\
\hline 6.1 & 1.28 & 82.9 & 199 & 8.7 & 21 & 5.4 & 13 & 3.0 & 07 & 0 & 0 & 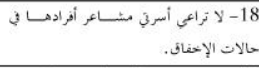 \\
\hline 6.1 & 1.34 & 81.6 & 196 & 9.6 & 23 & 3.3 & 08 & 3.3 & 08 & 2.1 & 05 & 16- ينعت والدي أفراد أستسرنه بأنسـاط \\
\hline 6.0 & 1.27 & 82.5 & 198 & 10.4 & 25 & 3.3 & 08 & 2.9 & 07 & 0.8 & 02 & 29 يغلب الشكت والقلق والحيرة على علاقتتا \\
\hline 5.8 & 1.21 & 87.9 & 211 & 5.4 & 13 & 3.7 & 09 & 2.9 & 07 & 0 & 0 & 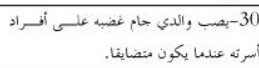 \\
\hline
\end{tabular}

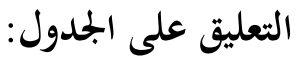

يتضح من البيانات الواردة في الجدول أن الفقرة (02) في المقياس والتي تنص على : إن إن

الوالد يحترم في رأى الغير بغض النظر على جنسه، من أكثر الفقرات شيوعا وتأتي في المرتبة الأولى، لمقياس طبيعة درجات التفاعل لقواعد ومعايير التفاعل للعلاقات الأسرية، في الجوانب الايجابية وبلغ وزها المئوي (21.2\%) كما شكلت نسبة (1.0\%) بدرجة مبعة قليلة جدا مقابل

$$
\text { نسبة (57.0\%) بدرجة كبيرة جدا. }
$$

تليها الفقرة (14) التي تنص: حرص الوالد على مناقشة الأمور بكل حرية ووضوح، حيث بلغ وزها المئوي (21.0 \% \%) وشكلت أعلى درجة على مقياس التدرج الخماسي ترهي لدرجات التفاعل للعلاقات الأسرية بدرجة كبيرة جدا نسبة (54.1\%) مقابل أقل نسبة على

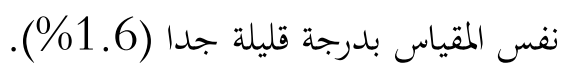
تساوت كل من الفقرة (23) التي تنص على أن الوالد يخصص الوقت الكافي لمناقشة الأمور لأبنائه الذكور والإناث على السواء وكذلك الفقرة (07) تنص على أن الحقوق تكون بالتساوي بين الأبناء بوزن مئوي بلغ (21.0\%) و تأتي في المرتبة الرابعة الفقرة (26) التي تنص على بنى (يبذل كل فرد في أسرتي جهده لتعيش في حياة سعيدة)، بوزن مئوي (20.4\%). 
كما تتساوى كل من الفقرات (15، 08، 17) التي تنص على التوالي: احترام الوالد الآراء بكل ود وتقدير، إتباع أسلوب التوجيه والنصح غير المباشر، والشعور بالاعتزاز بالأسرة

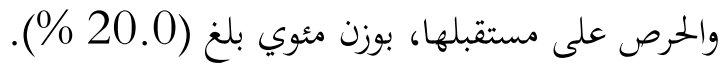
تأتي في المترتبة السادسة الفقرة (09) التي تنص على: الثقة المتبادلة والصدق أساس بلى التعامل بين أفراد الأسرة بوزن مئوي (19.8\%). وشكلت أعلى درجة على مقياس التدرج

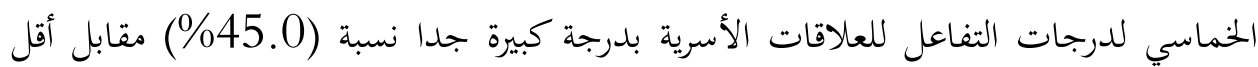
نسبة على نفس المقياس بدرجة قليلة جدا (4.2\%).

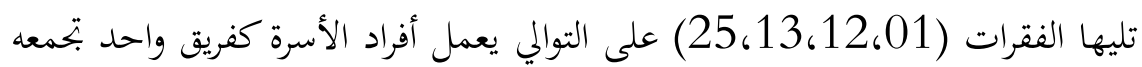
المحبة، تكافي الأسرة المحسن وتعاقب المسيء دون تميز، شعور الأبناء بان والدهم ينظر إليهم كأشخاص ناجحين، بالإضافة إلى الفقرة التي تنص (تناول وجبات طعام الغذاء والعشاء جميع إفراد الأسرة معاً) في المرتبة السابعة بوزن مئوي (19.2\%) على مقياس التدرج الخماسي لقواعد ومعايير التفاعل للعلاقات الاجتماعية الأسرية. تليها في الترتيب تنازليا، الفقرة (21) التي تنص على: (يحترم والدي وجهة نظر أبنائه في الحياة والاعتماد على قدراتم)، والتي بلغ وزغا المئوي (18.6 \%) وشكلت أعلى درجة على مقياس التدرج الخماسي لدرجات التفاعل للعلاقات الأسرية بدرجة كبيرة جدا نسبة (40.0\%) مقابل أقل نسبة على نفس المقياس بدرجة قليلة جدا (5.1\%). تم تأتي الفقرة (04) والتي تنص: (على الشعور بتقبل والدهم لهم بكل حسناقم

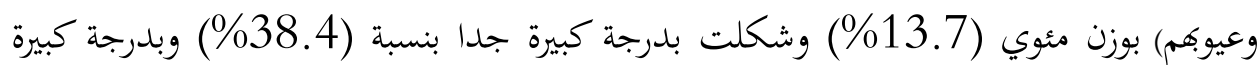

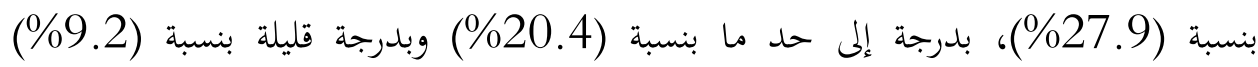

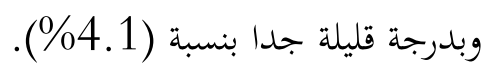
تم تليها لفقرة رقم (06) والتي تنص: (بعض أفراد الأسرة يبقون خارج البيت لساعات

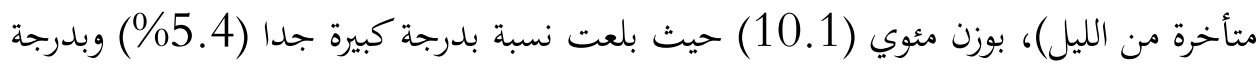


كبيرة بنسبة (7.1\%)، وبدرجة إلى حد ما بنسبة (21.0\%) وبدرجة قليلة بنسبة (27.5\%)


أما الفقرة الخامسة والتي تنص: (أن الوالد يخطئ في حق الأسرة رغم حبه لهم)، التي بلغ وزها المئوي (9.3\%) والتي بلغت بدرجة قليلة جدا نسبة (46.3\%) تليها تنازليا نسبة بدرجة قليلة (24.6\%) تم درجة إلى حد ما بنسبة (16.2\%) ونسبة بدرجة كبيرة (26.2\%) وتأتي

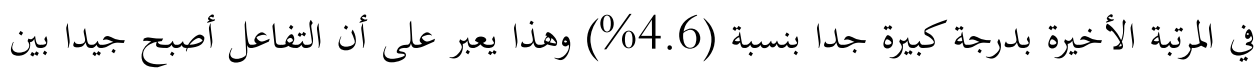

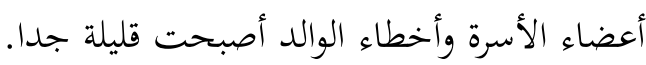

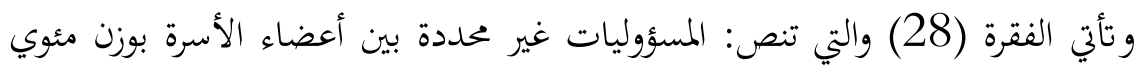

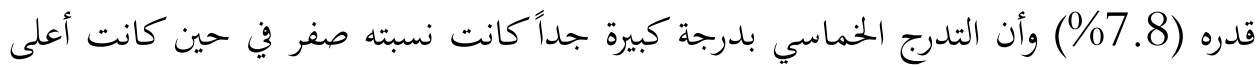

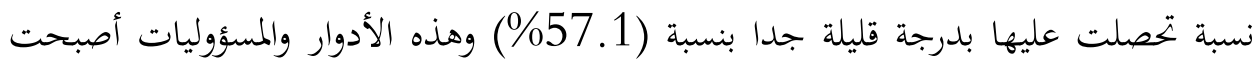
تتوزع بين أفراد الأسرة.

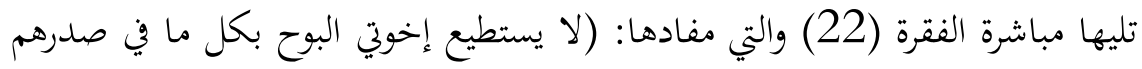

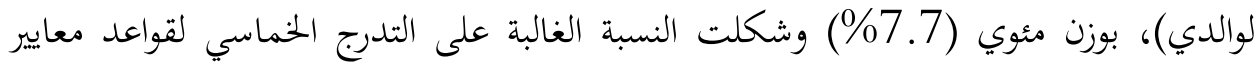

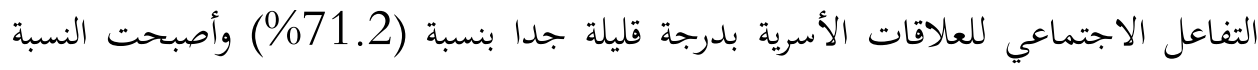

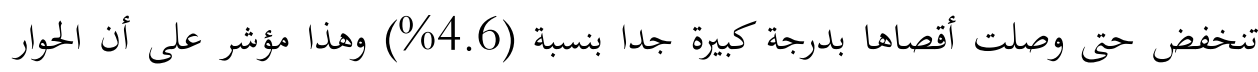
والمناقشة أصبح يسود بين أفراد الأسرة.

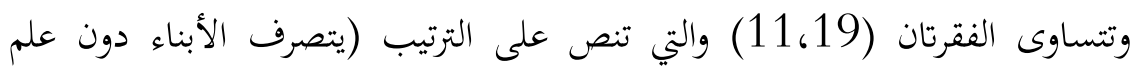

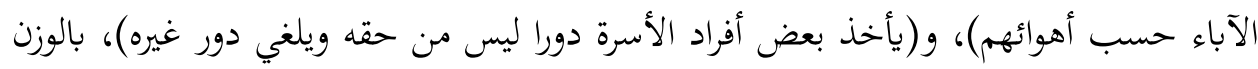

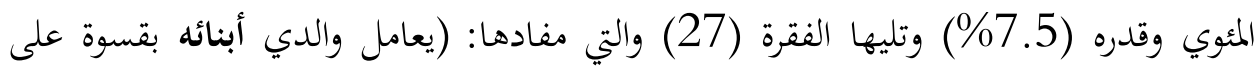

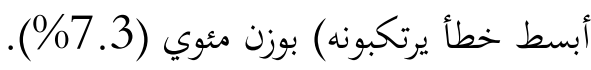

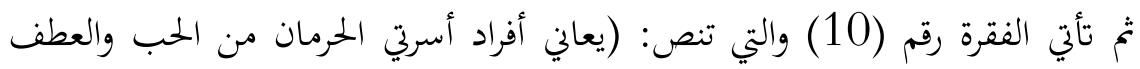

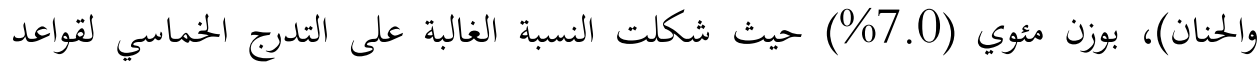

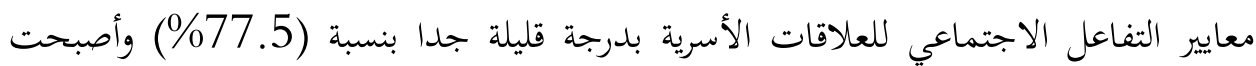


النسبة تنخفض حتى وصل أقصاها بدرجة كبيرة جدا بنسبة (2.5\%) وهذا مؤشر على أن الدفء العاطفي والحب والحنان أصبح يسود بين إفراد الأسرة.

تليها الفقرة (20) والتي تنص: (يتخلى بعض أفراد الأسرة عن دوره ويتهرب من

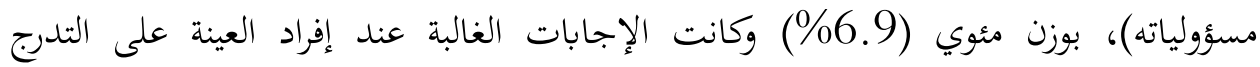



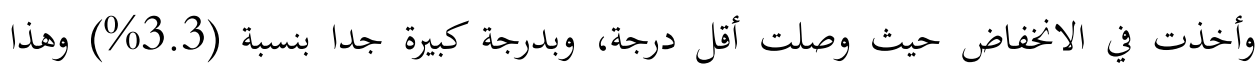
مؤشر ودليل على تفاعل الأسرة وفهم كل أعضائها الدور المنوط به.

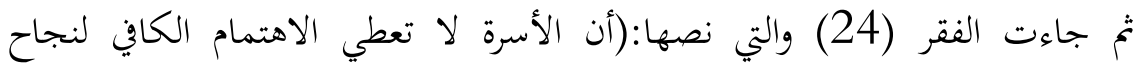

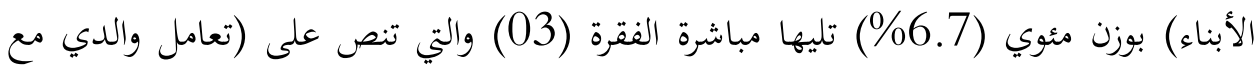

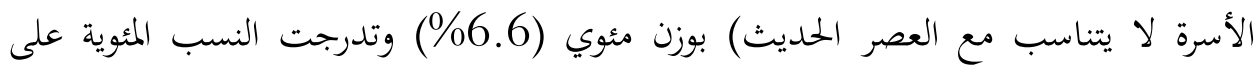

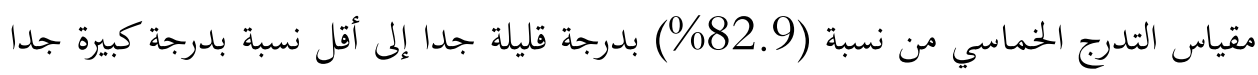
بنسبة (0.4).

وتساوت كل من الفقرة (16،18) والتي تنص على التوالي (ينعت والدي أفراد الأسرة

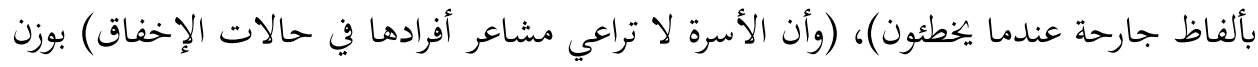


والقلق على أفراد الأسرة) بوزن مئوي (6.0) في حين جاءت في المرتبة الأخيرة الفقرة (30) والتي تقول بأن (الوالد يصب جام غضبه على أفراد الأسرة حين يكون متضايقا) بوزن مئوي .(\%5.8)

يلاحظ أن الفقرات التي تتسم بالجوانب السلبية لقواعد معايير التفاعل الاجتماعي لطبيعة العلاقات داخل الأسرة، جاءت أقل درجات في المقياس، من حيث الأهمية لدى أفراد العينة، في حين إن الفقرات التي تتسم بالإيجابية على درجات المقياس لقواعد معايير التفاعل الاجتماعي للعلاقات الاجتماعية الأسرية جاءت أعلى درجات المقياس. 
هذا يتضح أن أساليب التعامل لقواعد معايير التفاعل الاجتماعي من خلال بجريات الحياة اليومية لطبيعة العلاقات الاجتماعية الأسرية، بين أعضاء الأسرة تأخذ الجوانب الإيجابية وتبتعد عن التقليدية التسلطية وتتجه نحو التحضر والحداثة.

\section{مناقشة نتائج البحث:}

ابته الاهتمام إلى الكشف عن قواعد ومعايير التفاعل الاجتماعي وإلى فحص طبيعة العلاقة الاجتماعية داخل الأسرة، فانطلقت الورقة من فرضية مفادها: أن المحددات الاجتماعية

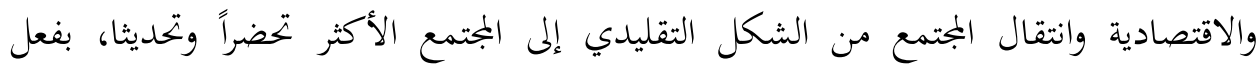
مؤشرات التحضر كالتعليم وخروج المرأة اتساع المشاركة في العمل، والتعرض لوسائل الاتصال، ونمو الحضرية كأسلوب وطريقة في الحياة، سيشهد النظام الاجتماعي للأسرة تحولا وتغيرا في درجات التفاعل الاجتماعي. يمكن تصنيف الورقة البحثية بأها دراسة وصفية تحليلية، حيث تم توظيف منهج مسحح العينة الوصفي في جمع البيانات، على وحدة التحليل والاهتمام في البحث، وهم طلاب مرحلة التعليم المتوسط، الذين تقع أعمارهم، ما بين سن (15 - 22) بمؤسسات التعليم المتوسط بمنطقة مصراتة. كما تم إتباع تصميم العينة العشوائية الطبقية، غير النسبية بشكل يراعي التفاوت

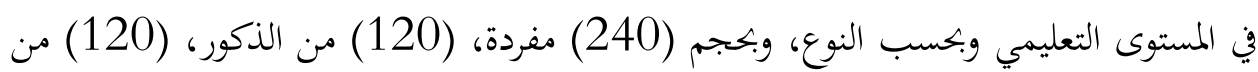
الإناث، الدراسيين بالسنة الأولى والسنة النهائية للعام الدراسي 2014 /2015. ولتقديم صورة واقعية لطبيعة العلاقة السائدة داخل الأسرة بالمجتمع اللبيي. فقد تم استخدام مجموعة من الأساليب الإحصائية، لتحليل بيانات متغير واحد، مثل الجداول التكرارية والنسب المئوية، إضافة إلى مقياس الوزن المئوي لتقدير الأهمية النسبية لفقرات مقياس درجات معايير التفاعل الاجتماعي. أشارت النتائج إلى أن أفراد العينة، هم أبناء أسر نووية كبيرة الحجم، تقيم في مناطق حضرية وانتقالية، بمستويات اقتصادية متوسطة، فالتعليم المتوسط يمثل النسبة الغالبة للآباء، 
ويشغلون مكانات وظيفية وحرفية في مستويات مقبولة، ويعيشون في ظروف سكنية ملائمة كما

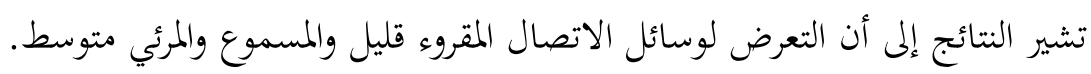
تشير نتائج الدراسة إلى وجود علاقة بين متغيرات المكانة الاجتماعية الاقتصادية الأسرية كالمستوى التعليمي ومهنة الأب ومقياس درجات معايير التفاعل داخل الأسرة، فالنتائج تشير إلى أن الزيادة في التعليم والمهنة يقابلها تحول في طبيعة العلاقة بين أعضاء الأسرة فالتعليم يعتبر مدخلا هاما يؤثر في طريقة التعامل، ويشكل ثقافة خاصة لأعضاء الأسرة تدفعهم لإعادة

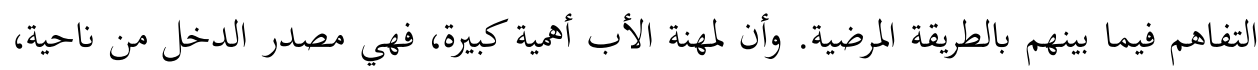

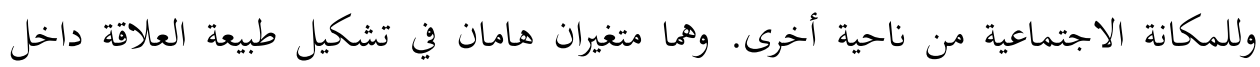
الأسرة، وإن كان أحداهما اقتصاديا والثاني اجتماعيا. فتعليم الأب ومهنته من العوامل المهمة التي تؤثر تأثيرا مباشراً في شخصية الأب والمشكلات التي يواجها، بما ينعكس على عادات التعامل مع الأبناء. وهذا يعني أن العلاقة الأسرية السائدة بين أعضاء الأسرة تتسم بالتفاعل الإيجابي، حيث تسود لغة الحوار والثقة المتبادلة، واحترام وجهات النظر داخل الأسرة الواحدة وما يرتبط بذلك من قواعد للسلوك والمعايير، حيث تجسد ذلك في علاقات طابعها المشاركة والاستقلالية والاقتحام والتقبل والاهتمام والمساواة في التعامل مع الأبناء ذكورا وإناثا. وفقا لمنطق نظرية التحديث، أن الأفراد الذين يقيمون في المناطق الحضرية أكثر ميلا في ارتفاع درجات التفاعل الاجتماعي داخل الأسرة. فإذا صارت الحضرية كطريقة وأسلوب للحياة فإها ستؤثر في مجرى الحياة الاجتماعية. وبذلك فإن طبيعة العلاقة بين أعضاء الأسرة تتجه نحو التفاعل. وبأن الأسرة تشكل حلقة الوصل بين الفرد والوسط الاجتماعي الذي يعيش فيه فبذلك تسهم في نقل وبحسيد التغير الثقافي الناجم عن مؤشرات التحديث، وبالتأكيد فإن إحدى الانعكاسات ستتشكل في صورة علاقات أكثر توجها نحو قواعد ومعايير أكثر تفاعلاً وإيجابية داخل المجتمع. 
يمكن القول بان النموذج التقليدي في طبيعة قواعد ومعايير التفاعل الاجتماعي داخل الأسرة لم يعد قائما كما كان، وفي الوقت ذاته فان النموذج الحديث لم يسد تماما بعد. واضح إذاً أن المرحلة الانتقالية -بين القديم والحديث- التي يمر بها المجتمع اللببي حاليا، قد انعكست على درجات التفاعل في طبيعية العلاقة الأسرية.

\section{التوصيات:}

في ضوء نتائج البحث يوصي الباحث بالآتي:

- زيادة نشر الوعي الثقافي بين الآباء من أجل تبني أساليب التعامل الإيجابي لقواعد السلوك المبني على المشاركة والحوار، والابتعاد عن التسلط والفردية، والزجر والنبذ والإهمال التي تدفع إلى تكوين شخصية غير قادرة على التكيف، مع التغيرات الاجتماعية المعاصرة. - حث الآباء من خلال وسائل الاتصال المختلفة، على تقوية العلاقات الأسرية وخاصة مع الأبناء، من خلال التفاعل الاجتماعي، وتبادل الأحاديث الجماعية لبعث الثقة وإعطاء فرصة لجميع أفراد الأسرة بالنقاش وإبداء الرأي والمشاركة في اتخاذ القرارات وبحمل المسؤولية. - الاهتمام برفع مستوى دخل الأسرة، لما له من أهمية في الاستقرار وتوفير المتطلبات

$$
\text { الاجتماعية الأسرية التي تتلائم مع ظروف العصر. }
$$

- إن دور الأب ليس التفكير بدلاً عن ابن، وإنما مساعدته على التفكير الصحيح والبعد عن فرض الوصاية على فكره، وعدم إلغاء عقله تحت دعوى أنه أكبر منه سنا، وأكثر منه خبرة ودراية وفهما، وكأنه يقول له لا تفكر، بل عليك أن تتبعني، فلابد للابن أن يملك خياره، فيصبح لديه القدرة على الرفض والقبول، بلا خوف أو تردد وأن تصبح طاعته وعلاقته مبصرة وليست عمياء. 
- كثير من الأبناء يتصرفون حسب توقعاتم لتصرفات الآباء تجاه تصرفاقم، ويتعايشون مع هذا التوقع، ويتأثرون بأقوال الآباء فيهم، ويينون الآراء عن أنفسهم وفقا لما يقوله الآباء عنهم، فإذا كان الابن محلا لثقة أبويه ومذكورا عندهما بالقدرة والنشاط والمبادرة والخلق الحسن، وإذا كان يلقى من التشجيع والتأييد والتوجيه ما يساعده على ذلك، فإنه يسعى لتأصل هذه الصفات في ذاته وجعلها سمة من سمات شخصيته وهذا ما تؤكده نظرية الوصم الاجتماعي إن كثير من تصرفات الفرد تكون حسب ما يلصقه الغير به. والسؤال التي تقف عليه هذه الورقة البحثية: هل هناك أسرة تعمل كيف تُعِدِ أبناءها أزواجا ناجحين، وبناتا زوجات ناجحات؟ 


\section{المصادر والمراجع}

1- أحمد السيد مُحَّة إسماعيل، مشكلات الطفل السلوكية، دار الفكر الجامعي، الإسكندرية، ط: 2،

2- بشرى الخالدي، العلاقة الصحيحة بين الآباء والأبناء، مركز الأبحاث العالمي، تاريخ الدخول

$$
\text { للموقع، } 21 \text { / } 2014 \text { / }
$$

3- - جيهان عبد العزيز محمود فرج، العلاقات بين الأجيال (بحث عن دور كبار السن في الأسرة المصرية بمدينة الفيوم) جامعة القاهرة، كلية الآداب، قسم علم الاجتماع، 1998. 4- سناء الخولي، الأسرة والحياة العائلية، دار النهضة العربية للطباعة والنشر والتوزيع، بيروت، .1984

5- عاطف غيث، قاموس علم الاجتماع، الإسكندرية، دار المعرفة الجامعية، 1990. 6- عبد السلام بشر الذويبي، علم النفس الاجتماعي منشورات جامعة طرابلس، ط1، .1998

7- عبد القادر القصير، الأسرة المتغيرة في مجتمع المدينة العربية، دار النهضة العببية، بيروت، ط 1999،

8- علاء الدين كقافي، تقدير الذاتي علاقته بالتنشئة الوالدية والأمن النفسي، دراسة في عملية تقدير الذات، مجلة العلوم الإنسانية، عدد 35، ب. ت، 1981م. 9- علي ليلة، النظرية الاجتماعية المعاصرة، (دراسة لعلاقة الإنسان بالمجتمع، الأنساق الكلاسيكية) مكتبة غريب، القاهرة، 1991. 10- مُحَّمَ بيومي خليل، سيكولوجية العلاقات الأسرية، القاهرة: دار قباء للطباعة والنشر والتوزيع، 2000. 
11- م مد لبيب النجيحي، الأسس الاجتماعية للتربية، دار النهضة العربية للطباعة والنشر، بيروت، بدون.

12- محمود السيد أبو النيل، علم النفس الاجتماعي، دار النهضة العربية للطباعة والنشر، بيروت، الجزء الثاني، 1978.

13- محمود فتحي عكاشة، محمود شفيق زكي، مدخل إلى علم النفس الاجتماعي المكتب المبت الجامعي الحديث، الإسكندرية، 1996. 14- مصطفى عمر التير، ابتحاهات التحضر في المجتمع العربي، الدار البيضاء، المؤسسة العربية

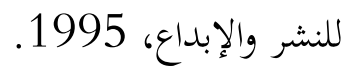
15- معن خليل معن، البناء الاجتماعي أنساقه ونظمه، دار الشروق، ط: 1، 1999. 16- هدى مُحَّم قناوي، الطفل وتنشئته وحاجاته، مكتبة الانجلو المصرية، القاهرة، 1988. 